\title{
Glucose 6-Phosphate Dehydrogenase from Trypanosomes: Selectivity for Steroids and Chemical Validation in Bloodstream Trypanosoma brucei
}

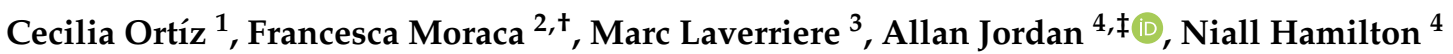 \\ and Marcelo A. Comini ${ }^{1, *(1)}$
}

1 Redox Biology of Trypanosomes, Institut Pasteur de Montevideo, Mataojo 2020, Montevideo 11400, Uruguay; cortiz@pasteur.edu.uy

2 Dipartimento di Biotecnologie, Chimica e Farmacia, Università degli Studi di Siena, Via Aldo Moro 2, 53100 Siena, Italy; francesca.moraca@gmail.com

3 Instituto de Investigaciones Biotecnológicas, Instituto Tecnológico de Chascomus (IIB-INTECH, UNSAM-CONICET), Av. General Paz 5445, INTI, San Martín 1650, Pcia de Buenos Aires, Argentina; marc.laverriere@pasteur.fr

4 Drug Discovery Unit, Cancer Research UK Manchester Institute, University of Manchester, Alderley Park, Macclesfield SK10 4TG, UK; a.jordan@sygnaturediscovery.com (A.J.); niall.hamilton@tiscali.co.uk (N.H.)

* Correspondence: mcomini@pasteur.edu.uy; Tel.: +598-2522-0910

+ Current affiliation: Schrödinger, Inc., 120 West 45th Street, New York, NY 10036, USA.

$\ddagger$ Current affiliation: Sygnature Discovery, Biocity, Pennyfoot Street, Nottingham NG1 1GR, UK.

Citation: Ortíz, C.; Moraca, F.;

Laverriere, M.; Jordan, A.; Hamilton, N.; Comini, M.A. Glucose 6-Phosphate Dehydrogenase from Trypanosomes: Selectivity for Steroids and Chemical Validation in Bloodstream Trypanosoma brucei. Molecules 2021, 26, 358. https:// doi.org/10.3390/molecules26020358

Academic Editor: Valeria

Patricia Sülsen

Received: 1 November 2020

Accepted: 9 January 2021

Published: 12 January 2021

Publisher's Note: MDPI stays neutral with regard to jurisdictional clai$\mathrm{ms}$ in published maps and institutional affiliations.

Copyright: (C) 2021 by the authors. Licensee MDPI, Basel, Switzerland. This article is an open access article distributed under the terms and conditions of the Creative Commons Attribution (CC BY) license (https:// creativecommons.org/licenses/by/ $4.0 /)$.
Abstract: Glucose 6-phosphate dehydrogenase (G6PDH) fulfills an essential role in cell physiology by catalyzing the production of $\mathrm{NADPH}^{+}$and of a precursor for the de novo synthesis of ribose 5-phosphate. In trypanosomatids, G6PDH is essential for in vitro proliferation, antioxidant defense and, thereby, drug resistance mechanisms. So far, $16 \alpha$-brominated epiandrosterone represents the most potent hit targeting trypanosomal G6PDH. Here, we extended the investigations on this important drug target and its inhibition by using a small subset of androstane derivatives. In Trypanosoma cruzi, immunofluorescence revealed a cytoplasmic distribution of G6PDH and the absence of signal in major organelles. Cytochemical assays confirmed parasitic G6PDH as the molecular target of epiandrosterone. Structure-activity analysis for a set of new (dehydro)epiandrosterone derivatives revealed that bromination at position $16 \alpha$ of the cyclopentane moiety yielded more potent T. cruzi G6PDH inhibitors than the corresponding $\beta$-substituted analogues. For the $16 \alpha$ brominated compounds, the inclusion of an acetoxy group at position 3 either proved detrimental or enhanced the activity of the epiandrosterone or the dehydroepiandrosterone derivatives, respectively. Most derivatives presented single digit $\mu \mathrm{M} \mathrm{EC}_{50}$ against infective T. brucei and the killing mechanism involved an early thiol-redox unbalance. This data suggests that infective African trypanosomes lack efficient $\mathrm{NADPH}^{+}$-synthesizing pathways, beyond the Pentose Phosphate, to maintain thiol-redox homeostasis.

Keywords: androstane; redox; Trypanosoma brucei; Trypanosoma cruzi; pentose phosphate pathway

\section{Introduction}

Chagas disease, African trypanosomiasis and leishmaniasis are "neglected tropical diseases" (NTD) that affect the most vulnerable populations around tropical and subtropical regions of the world. More than 100 million persons suffer from trypanosomiasis and leishmaniasis, and several thousand die annually [1] due to difficulties in access to treatments that, in terms of efficacy and safety, are far from ideal [2,3]. These are zoonotic diseases caused by digenetic protozoan (Familiy Trypanosomatidae) that evolved several unusual biochemical and structural characteristics to overcome the challenging environmental conditions imposed by their complex life cycles [4]. In this context, components of key metabolic pathways eral enzymes producing or depending on NADPH have raised 
interest as promising drug targets against trypanosomatids [5-9]. NADPH is an essential molecule that provides reducing power for the biosynthesis and repair of macromolecules, as weare very attractive for the development of potent and selective drugs. Among them, sevll as for the detoxification of xenobiotics and different reactive species derived from partial reduction of oxygen or from nitric oxide.

Several enzymes may contribute to the production of NADPH in different subcellular compartments of the infective stages of trypanosomatids [10,11]. They can be grouped in dehydrogenases participating in amino acid (isocitrate dehydrogenase: IDH, malate dehydrogenase: $\mathrm{MDH}$, glutamate dehydrogenase: GDH) or carbohydrate metabolism (glucose 6-phosphate dehydrogenase: G6PDH and 6-phosphogluconate dehydrogenase: 6PGDH). Such redundancy enables the parasite to maintain the NADPH pool under different growth conditions. For instance, in glucose-rich media (e.g., mammalian bloodstream, lymph and cerebrospinal fluid), African trypanosomes rely on glucose 6-phosphate oxidation by enzymes (i.e., G6PDH and 6PGDH) that belong to the oxidative branch of the pentose phosphate pathway (PPP) to synthesize NADPH [11]. Under glucose starvation, the flux through the oxidative branch of the PPP is reduced and NADPH homeostasis is mainly sustained by a transhydrogenase-like shunt involving cytosolic and mitochondrial $\mathrm{MDH}$ [11]. Nonetheless, a significant amount of cytosolic NADPH has been shown to be produced by the PPP (ca. 25\% in bloodstream T. brucei) due to gluconeogenesis fueled by glycerol (in the mammalian stage) [12] or proline (in the insect stage) [13]. G6PDH [14] and 6PGDH [15] proved indispensable for the bloodstream form of T. brucei, though it remains unclear whether this is a consequence of a shortage of NAPDH and/or ribose 5-phosphate. For T. cruzi, several NADP-dependent dehydrogenases have been characterized [16-22] but a quantitative assessment of their contribution to NADPH homeostasis in the infective stages has not yet been performed. In the mammalian host and at variance with T. brucei, T. cruzi can colonize different host cells and obtain reducing equivalents from amino acid metabolism via the Krebs' cycle [23]. Nonetheless and independently of the cell cycle stage, the oxidative branch of the PPP appears to efficiently back up the NADPH demand of T. cruzi upon oxidative challenge. In fact, treatment of parasites with $\mathrm{H}_{2} \mathrm{O}_{2}$ [19] or the redox cycling drug methylene blue upregulated the expression of G6PDH and the rate of glucose consumption through the PPP [24,25], respectively.

Due to its house-keeping role in metabolism, G6PDH has raised special interest as a drug target candidate to treat trypanosomal [11,26] and non-communicable human diseases, such as cancer $[27,28]$. Among the molecules with potential to inhibit G6PDH, the steroid derivatives represent the first and best characterized inhibitors of the human [27,29-31] and pathogen enzyme [14,32-34]. (Dehydro)epiandrosterone derivatives were described as anti-competitive inhibitors of G6PDH [14] whose inhibitory potential and selectivity can be tuned by including specific substituents at positions 3 or $16[27,33]$. Taking advantage of the availability of crystal structures for the human [35-37] and T. cruzi G6PDH [22,38], the potential binding site of steroids to these enzymes have been investigated. In silico studies performed on the structure of the binary G6PDH-G6P complex suggested that steroids partially occupy the NADP+ binding site of the human enzyme [39], which in part conflicts with the proposed uncompetitive inhibition kinetics described for these compounds. In contrast, and according to data arising from complementary computational and biochemical analysis, the steroids were proposed to bind to T. cruzi G6PDH in a region next to the G6P-binding pocket and close to the catalytic site [33].

The metabolic relevance of G6PDH and its selective drugability by steroids encouraged us to characterize the subcellular localization of the protein in a pathogen parasite, to demonstrate the on-target/mode of killing of EA and DHEA derivatives in infective trypanosomes and to provide some clues on the molecular determinants for the differential binding mode of these compounds to the host and parasite enzyme. In the present study, all of these questions are subjects of investigation. 


\section{Results and Discussion}

2.1. G6PDH Is a Low Abundant and, Predominantly, Cytosolic Protein in Non-Infective T. cruzi

Specific polyclonal antibodies against TcG6PDHL were raised in mice [22] and used for Western blot and immunofluorescence analysis in the insect stage of T. cruzi. In line with previous observations [18], immune-detection (blotting or microscopy) of endogenous G6PDH proved unsuccessful in epimastigote parasites (Figure 1A), which confirms that $\mathrm{G} 6 \mathrm{PDH}$ is a low abundant protein in the non-infective stage of the parasite.

A
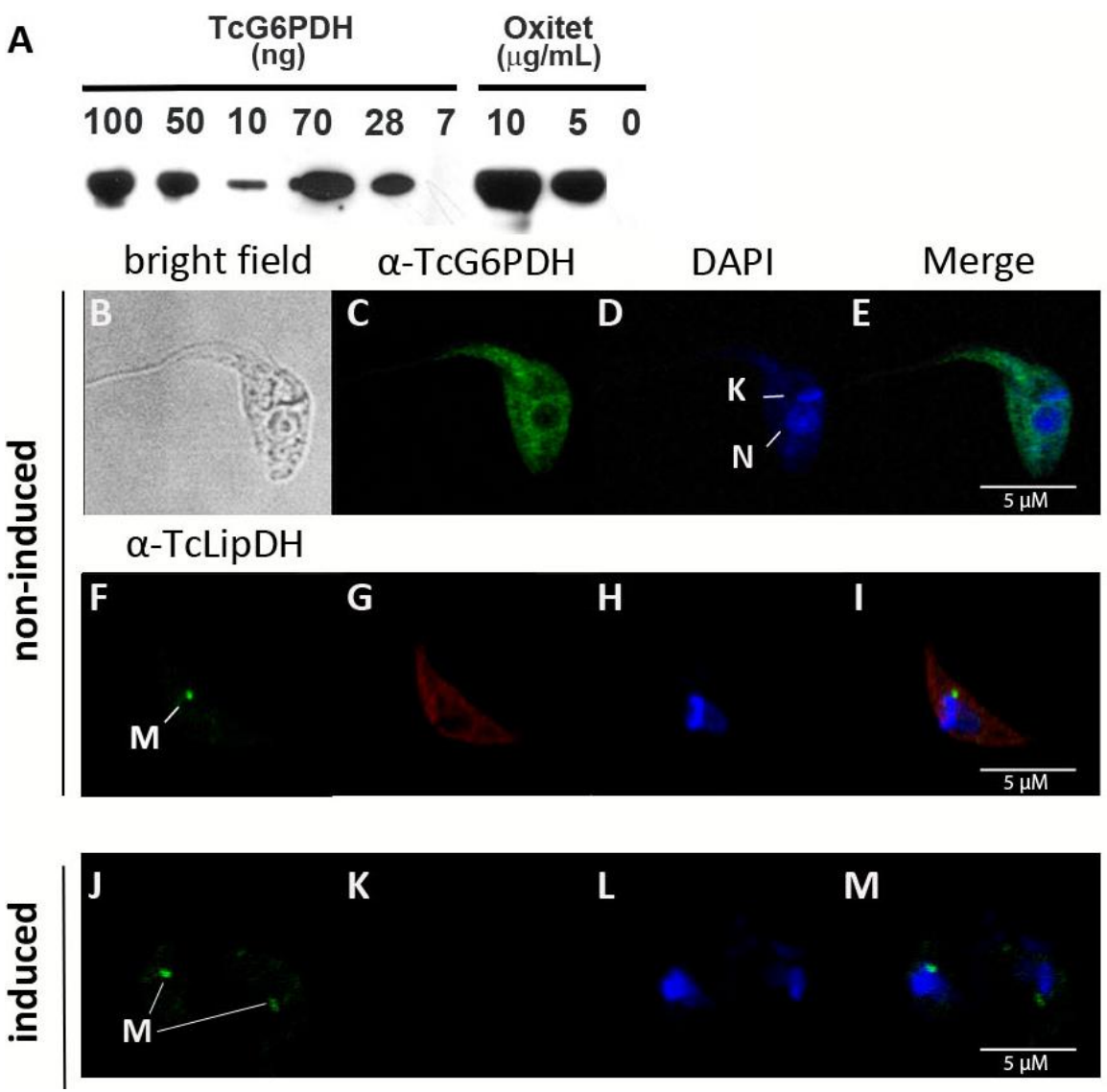

Figure 1. Subcellular distribution of G6PDH in T. cruzi epimastigotes (strain Adriana). (A) Western blot analysis of different amounts of recombinant $\operatorname{TcG6PDH}(7,10,28,50,70$ and $100 \mathrm{ng})$ and cell extracts of oxytetracycline induced ( 5 or $10 \mu \mathrm{g} / \mathrm{mL}: 1 \times 10^{7}$ cells/lane) and non-induced $(0 \mu \mathrm{g} / \mathrm{mL}$ : $1 \times 10^{6}$ cells/lane) trypanosomes. Confocal microscopy of samples from induced (B-I) and noninduced (J-M) parasites. (C,G,K) Indirect immunofluorescence using anti-TcG6PDHL and secondary anti-mouse serum conjugated to Alexa 488 (green signal) or Alexa 594 (red signal), respectively. $(\mathbf{D}, \mathbf{H}, \mathbf{L})$ Mitochondrial (K) and nuclear (N) DNA was stained with DAPI (blue signal). (F,J) signal corresponding to the mitochondrial lipoamide dehydrogenase (M) detected with specific anti-serum against the T. cruzi protein. (E,I,M) Merge images of the fluorescence staining.

In order to overcome this limitation and estimate the intracellular concentration and subcellular localization of the protein, a tetracycline-inducible ectopic copy of TcG6PDHL was expressed in T. cruzi. As shown in Figure 1A, G6PDH became detectable in total lysates from transgenic parasites cultured in the presence of oxytetracycline but not in its absence. Based on the detection limit of the antibodies (up to $10 \mathrm{ng}$ TcG6PDHL), the total cell number in the analyzed lysate and the cell volume reported for T. cruzi epimastigotes (30 fL) [40], we estimated that the intracellular concentration of G6PDH in this parasite species and stage is lower than $0.7 \mu \mathrm{M}$.

Immunofluorescence using the anti-G6PDH serum and secondary antibodies labeled with different fluorophores revealed a predominantly cytosolic distribution of the protein 
in T. cruzi from the Adriana (Figure 1B,D) and CL-Brener strain (Figure S1). The G6PDH signal did not overlap with that obtained for the nucleus or the mitochondrial protein lipoamide dehydrogenase (Figure 1C,E) [41,42]. Unfortunately, we were unable to detect G6PDH in total cell lysates of T. brucei, even when using a higher concentration of TcG6PDH anti-serum (not shown), which can be ascribed to the lack of strong cross-reactivity of the antibodies or to a lower intracellular content of this protein in African trypanosomes.

To further confirm these results, we employed a cytochemical assay where the in situ production of NADPH by G6PDH is coupled to the formation of fluorescent formazan salts via the electron carrier methoxyphenazine methosulphate [43]. In order to ensure the specificity of the NADPH source, mitochondrial energetic metabolism is shut-off through the addition of sodium azide and G6P/NADP ${ }^{+}$. As shown in Figure 2, a formazan signal was confined to parasite cytosol of G6PDH overexpressing parasites and was fully absent in samples where G6P was omitted as a substrate (Figure S1A-D). This assay also allowed the detection of the cytosolic signal from the endogenous G6PDH activity in non-induced parasites (Figure S1E).
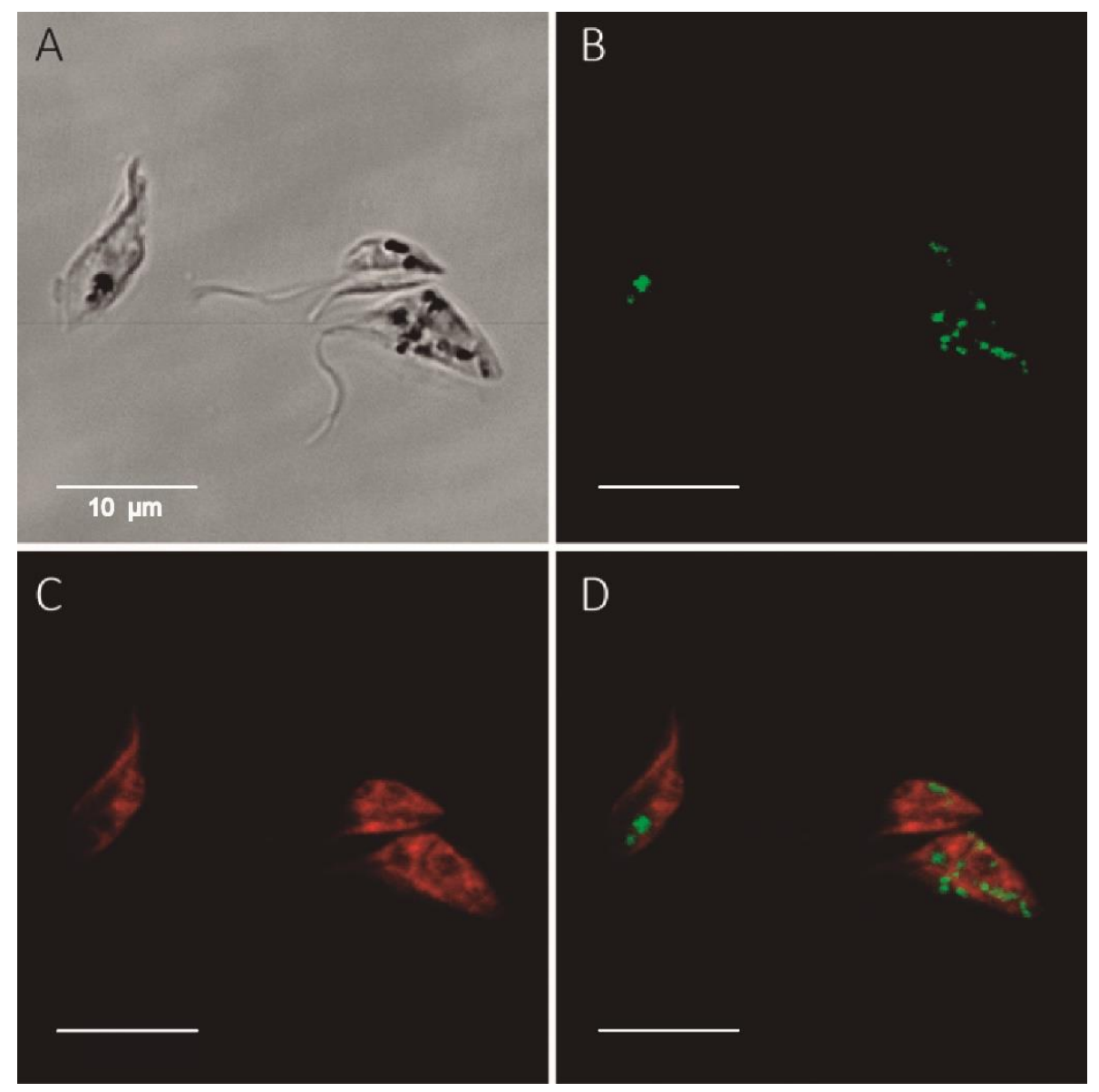

Figure 2. In situ detection of G6PDH activity in T. cruzi overexpressing G6PDH. Epimastigotes ( $T$. cruzi strain Adriana) were grown for $24 \mathrm{~h}$ in the presence of $10 \mu \mathrm{g} / \mathrm{mL}$ oxytetracycline to induce overexpression of TcG6PDHL (Western blot shown in Figure 1A). The formazan fluorescent signal (green color) generated by the NADPH-dependent reduction of 5-cyano-2,3-ditolyl-tetrazolium chloride corresponds to G6PDH activity. (A) Bright field image with light dense intracellular particles corresponding to precipitated formazan salt. (B) Fluorescent formazan signal. (C) Cell membranes stained with CellMask. (D) Merged image of the fluorescence staining.

\subsection{Epiandrosterone (EA) Targets G6PDH in T. cruzi}

The only and indirect evidence showing that steroids target G6PDH at the cellular lever stems from assays performed on a T. brucei cell line that was genetically engineered to 
express the Leishmania mexicana G6PDH [32]. Unlike the trypanosomal G6PDH, L. mexicana, G6PDH is refractory to EA and DHEA inhibition [14], hence T. brucei expressing the leishmanial enzyme was resistant to these steroids.

In order to provide direct evidence for the on-target effect of steroids in T. cruzi, epimastigotes from different strains (CL-Brener and Dm28c) were treated for $24 \mathrm{~h}$ with different concentrations of EA $(0-100 \mu \mathrm{M})$ and G6PDH activity was measured in the supernatant of cell lysates and in situ using the cytochemical assay described above. For both T. cruzi strains, the specific G6PDH activity measured in cell extracts decreased in a concentration-dependent manner with respect to EA (Figure 3 for strain CL-Brener and Figure S2 for Dm28C). Similarly, the cytochemical assay revealed a discrete fluorescence staining of the cytosol for untreated parasites that decreased in intensity or was absent in samples treated with increasing concentrations of EA (Figure 3 and Figure S2). The percentage of cells displaying positive signal for G6PDH activity at the different EA concentrations is shown in Figure S2.
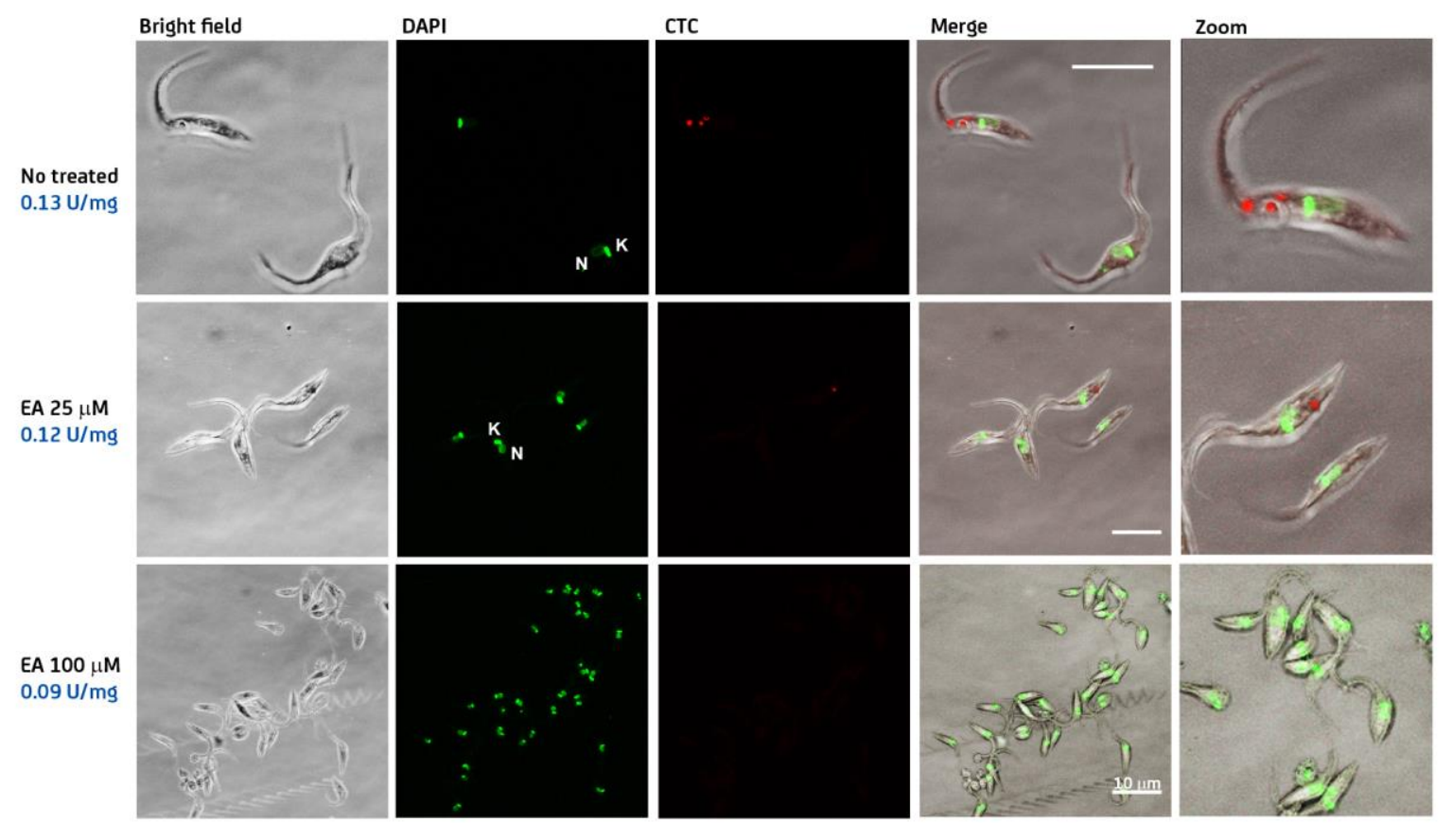

Figure 3. In situ detection of G6PDH activity in T. cruzi strain CL Brenner. Epimastigotes were incubated for $24 \mathrm{~h}$ in the absence (no treated) or presence of 25 and $100 \mu \mathrm{M}$ epiandrosterone (EA). G6PDH activity was measured in cell extracts using the standard enzyme assay (specific activity expressed as $\mathrm{U} / \mathrm{mg}$ ) and detected at intracellular level using a couple cytochemical assay based on the reduction of 5-cyano-2,3-ditolyl-tetrazolium chloride (CTC; red color). Hoechst 3342 (green color) was used to stain nuclear and mitochondrial DNA. Bright field and merged images are also shown with the white bar indicating a length of $10 \mu \mathrm{m}$.

These results strongly suggest that the major molecular target of EA in T. cruzi is G6PDH.

\subsection{Inhibition of G6PDH by New (Dehydro)Epiandrosterone Derivatives}

According to previous molecular and biochemical studies [33], substitutions at the cyclopentane ring and position 3 of steroids can fine-tune the inhibitory potential of these molecules against TcG6PDH (Figure 4). For instance, bromination of EA and DHEA at position 16 yielded very potent and selective TcG6PDH inhibitors [14]. However, the relevance of the halogen orientation ( $\alpha$ or $\beta$ ) for enzyme inhibition has not yet been addressed. On the other hand, polar substituents were well tolerated at position 3, yielding slightly better inhibitors of TcG6PDH than unsubstituted EA [33]. 


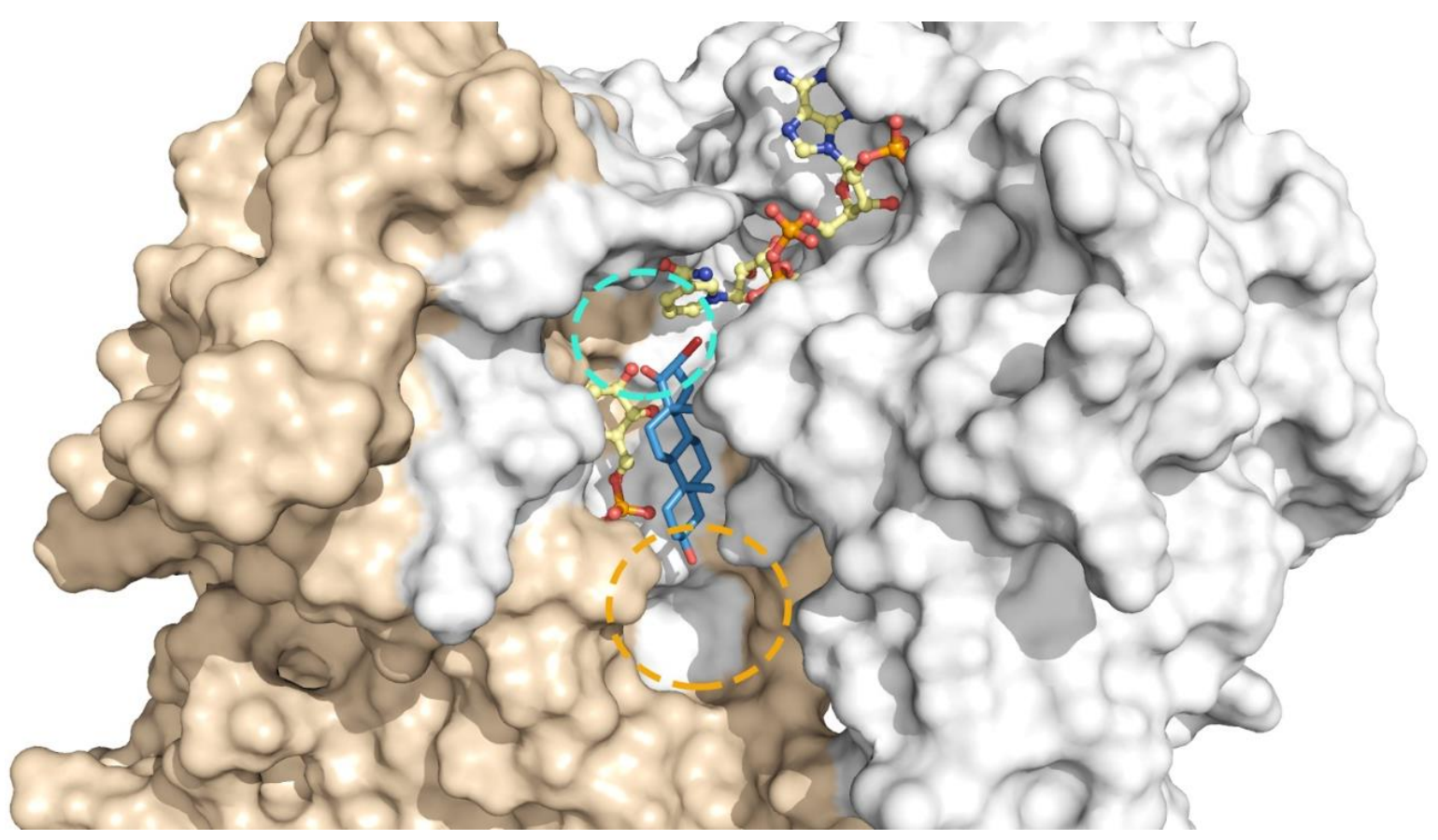

Figure 4. Docking of 16 $\alpha$-bromo-epiandrosterone to T. cruzi G6PDH. Catalytic model of TcG6PDH (NADP+ and G6P are shown in yellow sticks) with bound bromo-epiandrosterone (blue sticks) [33]. The N-terminal Rossmann-fold and the C-terminal dimerization domain of TcG6PDH are shown as surface colored in light-gray and wheat color, respectively. The protein pockets and positions of the steroids that are suited for substitutions are circled in cyan and orange.

Nonetheless, the role of apolar substituents at position 3 was not explored. Thus, here we addressed these questions by investigating the performance of a small subset of 3-acetoxy, $16 \alpha$ and $16 \beta$ brominated EA and DHEA derivatives towards the recombinant form of the pathogen and human G6PDH (Figure 5). Conesine, a steroid alkaloid containing a pyrrole ring at the pentane moiety and with very potent anti-T. brucei activity [44], was also analyzed.

\section{epiandrosterone} analogues

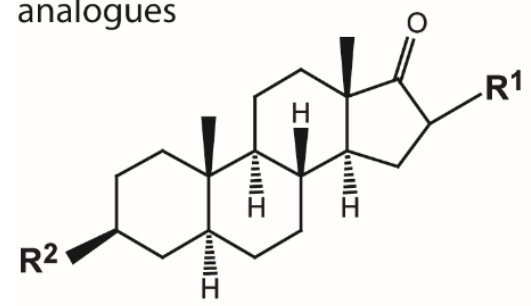

$E A: R^{1}=\mathrm{O}, \mathrm{R}^{2}=\mathrm{OH}$

1: $\mathrm{R}^{1}=\mathrm{aBr}, \mathrm{R}^{2}=\mathrm{OH}$

2: $\mathrm{R}^{1}=\mathrm{aBr}, \mathrm{R}^{2}=\mathrm{OAC}$

3: $R^{1}=\beta B r, R^{2}=O A C$

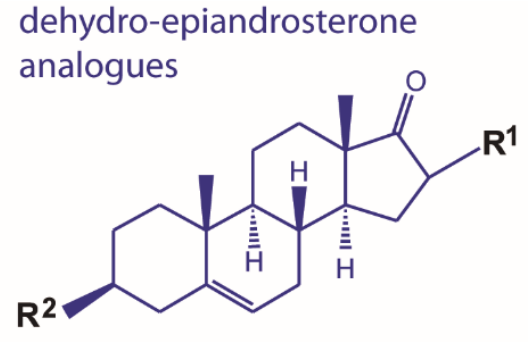

DHEA: $\mathrm{R}^{1}=\mathrm{O}, \mathrm{R}^{2}=\mathrm{OH}$

4: $\mathrm{R}^{1}=\mathrm{aBr}, \mathrm{R}^{2}=\mathrm{OH}$

5: $\mathrm{R}^{1}=\mathrm{aBr}, \mathrm{R}^{2}=\mathrm{OAC}$

6: $R^{1}=\beta B r, R^{2}=O A C$

7: $\mathrm{R}^{1}=\mathrm{OH}, \mathrm{R}^{2}=\mathrm{OH}$

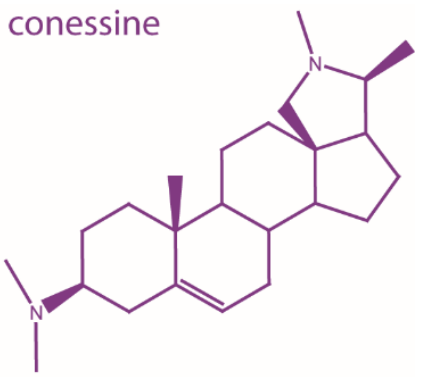

Figure 5. Steroid analogues tested in this study.

In agreement with a previous report [14], DHEA and EA displayed a similar inhibitory activity towards human $\mathrm{G} 6 \mathrm{PDH}\left(\mathrm{IC}_{50} \sim 10 \mu \mathrm{M}\right)$, whereas the latter was 7-fold more active against TcG6PDH $\left(\mathrm{IC}_{50}=3 \mu \mathrm{M}\right.$; Table 1). Interestingly, the inclusion of an H-bond donor group $(\mathrm{OH})$ at position 16 of DHEA did not significantly modify the potency towards the human enzyme $\left(7, \mathrm{IC}_{50}=15.8 \mu \mathrm{M}\right)$ but instead proved to be detrimental for inhibition of TcG6PDH $\left(7, \mathrm{IC}_{50}>50 \mu \mathrm{M}\right)$. Interestingly, $16 \alpha$-bromination of the cyclopentane moiety had profound effects on the potency and selectivity of the steroids towards the molecular targets. 
Compared to the parent molecules, $16 \alpha$-BrEA $\left(1, \mathrm{IC}_{50}=0.053 \mu \mathrm{M}\right)$ and $16 \alpha-\operatorname{BrDHEA}(4$, $\mathrm{IC}_{50}=3.3 \mu \mathrm{M}$ ) showed a 56- and 7-fold higher levels of inhibitory activity against TcG6PDH, respectively. Conversely, against the human enzyme both brominated derivatives were 2to 4 -fold ( $\left(\mathrm{IC}_{50}=20.8\right.$ and $48.0 \mu \mathrm{M}$ for $16 \alpha$-BrEA and $16 \alpha$-BrDHEA, respectively) less active than the unmodified steroids. A similar selectivity towards TcG6PDH was reported for 16BrEA [26]. Thus, halogenation of EA and DHEA increased the selectivity of the steroids for the pathogen vs. the host enzyme by 130 - and 28 -fold, respectively.

Table 1. Inhibition of G6PDH by (dehydro)epiandrosterone derivatives.

\begin{tabular}{cccc}
\hline \multicolumn{3}{c}{ IC $_{\mathbf{5 0}}(\boldsymbol{\mu M})$} \\
\hline Compound & T. cruzi & H. sapiens & Selectivity Index $^{\mathbf{b}}$ \\
\hline EA & $3.0 \pm 0.4^{\mathrm{c}}$ & $9.4 \pm 1.0^{\mathrm{a}}$ & 3 \\
$\mathbf{1}$ & $0.053 \pm 0.002$ & $20.8 \pm 4.4^{\mathrm{a}}$ & 392 \\
$\mathbf{2}$ & $0.11 \pm 0.02$ & $>100$ & $>909$ \\
$\mathbf{3}$ & $1.5 \pm 0.2^{\mathrm{d}}$ & $>100$ & $>67$ \\
DHEA & $21.5 \pm 0.5^{\mathrm{d}}$ & $11.3 \pm 2.2^{\mathrm{a}}$ & 0.5 \\
$\mathbf{4}$ & $3.3 \pm 0.7$ & $48.0 \pm 2.6$ & 14 \\
$\mathbf{5}$ & $0.079 \pm 0.01$ & $>100$ & $>1266$ \\
$\mathbf{6}$ & $>50$ & $>100$ & $>2$ \\
$\mathbf{7}$ & $>50$ & $15.8 \pm 3.3^{\mathrm{a}}$ & 0.32 \\
Conessine & $>100$ & $>100$ & $\mathrm{ND}$ \\
\hline
\end{tabular}

${ }^{\mathrm{a}} \mathrm{IC}_{50}$ values reported in [27]; ${ }^{\mathrm{b}}$ selectivity index calculated as $\mathrm{IC}_{50}$ for human $\mathrm{G}_{\mathrm{PDH}}$ vs. $\mathrm{IC}_{50}$ for T. cruzi G6PDH Data reported in ${ }^{\mathrm{c}}[33]$ or ${ }^{\mathrm{d}}$ in [14].

The inclusion of an apolar acetoxy group at position 3 of $16 \alpha$-brominated EA (2) and DHEA (5) almost abrogated the inhibition of human G6PDH ( $0 \%$ inhibition at $100 \mu \mathrm{M}$ compounds). With respect to TcG6PDH and when compared to the 3-unmodified molecules, the acetoxy group proved to be slightly detrimental for the activity of $16 \alpha$-BrEA (2, $\left.\mathrm{IC}_{50}=0.11 \mu \mathrm{M}\right)$ but significantly enhanced activity for $16 \alpha$-BrDHEA $\left(5, \mathrm{IC}_{50}=0.079 \mu \mathrm{M}\right)$. Indeed, the loss of human G6PDH inhibition conferred by the incorporation of the acetoxy group along with the submicromolar activity against the pathogen enzyme resulted in both compounds showing the highest selectivity towards TcG6PDH $(>900)$ ever reported.

Notably, for the acetoxy derivatives the orientation of the halogen atom appears to be a key determinant for the anti-TcG6PDH activity, since the EA and DHEA analogues harboring a $\beta$ - $\mathrm{Br}$ were $13-\left(3, \mathrm{IC}_{50}=1.5 \mu \mathrm{M}\right)$ and $>600$-fold $\left(6, \mathrm{IC}_{50}>50 \mu \mathrm{M}\right)$ less active than the $\alpha$-Br analogues ( 2 and 4 , respectively). Against the human enzyme and similar to the $\alpha$-Br analogues, both $\beta$-brominated 3-acetoxy steroids proved to be inactive at $100 \mu \mathrm{M}$, indicating that the acetoxy group to a great extent affects the binding of the steroids to the host protein.

At the highest concentration tested $(100 \mu \mathrm{M})$, Conesine did not inhibit G6PDH from both species, which demonstrated that this is not its molecular target.

\subsection{Differential Binding Mode of Steroids to Human and T. cruzi G6PDH}

The remarkable selectivity of the new acetoxy derivatives of $16 \alpha$-BrEA or DHEA is suggestive of major differences in the binding mode/affinity of these compounds for the human and parasite enzyme. In order to provide some preliminary clues towards this question, the potential binding mode of the EA analogues to T. cruzi and human G6PDH was modeled using computational approaches (Figure 6). Based on the fact that steroids inhibit G6PDH from both species by an anticompetitive mechanism [14,31], the analysis was performed for each enzyme-substrates complex. In this study, we saved three docking poses per ligand and we chose the best one based on the docking score combined with how many times a pose would be duplicated among the three saved as an indication of a higher consistency (and perhaps stability) of the pose itself. Indeed, two out of three poses were found to be overlaid in the docking performed on T. cruzi G6PDH for all compounds. For the human G6PDH, two out of three poses only overlay for EA, $16 \alpha$-BrEA and 16 $\beta$-BrEA. 
Compounds $\mathbf{2}$ and 3 show a very different binding mode in all the three poses saved, indicating that none of the contacts is favorable enough to stabilize a pose.

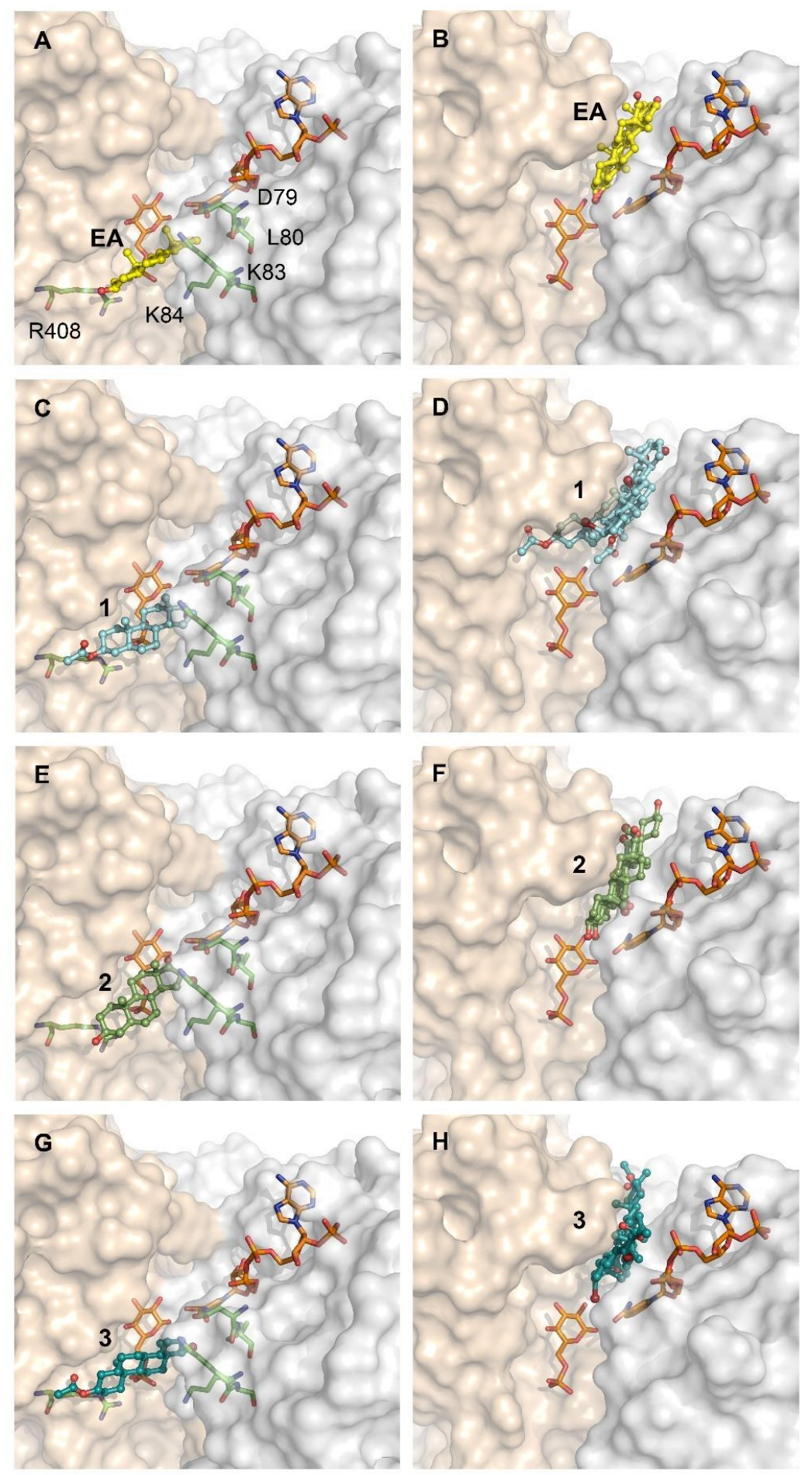

Figure 6. Docking of steroids derivatives to T. cruzi and human G6PDH. Catalytic model of TcG6PDH (left side) and HsG6PDH (right side), $\mathrm{NADP}^{+}$and G6P are shown in orange sticks. (A,B) with bound epiandrosterone (yellow balls and sticks), (C,D) compound $\mathbf{1}$ (cyan balls and sticks), (E,F) compound 2 (green smudge balls and sticks), (G,H) compound $\mathbf{3}$ (deep teal balls and sticks). The N-terminal Rossmann-fold and the C-terminal dimerization domain of TcG6PDH is shown as surfaces colored in light-gray and wheat color, respectively. Residues involved in steroid binding to TcG6PDH: D79, L80, K83, K84 and R408 are depicted with green sticks in (A,C,E,G). 
In agreement with our previous studies (Figure 4) [33], the binding site of the new steroids to TcG6PDH lies in a pocket beneath that of G6P (Figure 6A,C,E,G). The cyclopentanone moiety of EA shows hydrophobic contacts with Y295, the cyclohexane in position 13-14 with the nicotinamide ring of $\mathrm{NAP}^{+}$and the methyl group in position 10 with $\mathrm{I} 287$. For $16 \alpha$-BrEA (1), its cyclohexane in position 5 makes additional contacts with K83 and the $\mathrm{Br}$ loses a contact with the nicotinamide ring, but maintains the ones with the $\mathrm{NAP}^{+}$ phosphate group and Y295. This slight reorganization in the protein-inhibitor contact and the steric effect of $\mathrm{Br}$ in the catalytic site may explain the higher potency of the brominated derivative. In line with their similar inhibitory activity towards TcG6PDH, the acetoxy derivative 2 shows a binding mode consistent with that of $16 \alpha$-BrEA. For compound 2, the methyl group in position 13 is oriented parallel to the G6P binding site and the $\mathrm{Br}$ oriented towards the $\mathrm{NAP}^{+}$, making hydrophobic contacts with the nicotinamide group, the phosphate group and also Y295. The cyclopentane makes hydrophobic interactions with Y295 as well, and the cyclohexane in position 13-15 interacts with the nicotinamide moiety of $\mathrm{NAP}^{+}$. The methyl group in position 10 makes hydrophobic contacts with $\mathrm{I} 287$. Overall, the orientation of the steroidal rings for compound 3 is similar to that of compound 2; however, the $\beta$-Br atom is now oriented towards the G6P binding site and the number of hydrophobic contacts is reduced. Specifically, the halogen atom shows contacts with only Y295; the cyclopentane does not show any contact with the enzyme nor the cofactor; the cyclohexane only shows contacts with the nicotinamide moiety of $\mathrm{NAP}^{+}$and the methyl group in position 10 maintains contacts with I287. This may explain the comparatively lower activity of compound 3 with respect to 1 and 2 ( $\mu \mathrm{M}$ vs. $n M$; Table 1 ).

Interestingly, the binding site of steroids to human G6PDH suggested by our analysis is very similar to that reported previously [39], except for the orientation adopted by the ligands that is shifted almost $90^{\circ}$ in the plane of the steroid rings. In fact, whereas in the model generated on the G6P-HsG6PDH complex the representative steroids partially occupied the substrate binding sites [39], our model shows that EA and its $16 \alpha$-Br derivative do not interfere with substrate binding and are tightly embedded in a hydrophobic pocket formed by the apolar side chains of Pro143, Pro144, Pro172 and Tyr249, and are located near the active site (Figure 6B,D). In the case of EA, our model shows that its cyclopentanone moiety makes hydrophobic contacts with P144 and P143; the cyclohexane in position 13-14, the methyl group in position 10 and the cyclohexane in position 10-5 are making hydrophobic contacts with F253. The cyclohexane in position 10-5 is in contact with the nicotinamide moiety of $\mathrm{NADP}^{+}$as well. The methyl group in position 13 makes hydrophobic contacts with Y249. For 16 $\alpha$-BrEA, the halogen atom makes hydrophobic contacts with E252 and F253; similar to EA, the cyclopentanone interacts with P144 and P143; the cyclohexane in position 13-14 makes hydrophobic contacts with F253 and Y249; both methyl groups are oriented towards the $\mathrm{NADP}^{+}$and the one in position 10 makes hydrophobic contacts with the nicotinamide moiety of $\mathrm{NADP}^{+}$together with the cyclohexane in position 10-5.

As commented on above, docking of 2 and 3 into HsG6PDH yielded poses that differed markedly between each other (rotations of $90^{\circ}$ and $180^{\circ}$ ) in the orientation of the steroid rings (and their methyl groups) and, consequently, affected the $3^{\prime}$-acetoxy substitution. This unstable binding is consistent with the experimental data (Table 1), namely that these compounds do not inhibit the human G6PDH, and can be attributed to the acetoxy group.

The different binding sites of steroids to human and T. cruzi G6PDH raises a question about the structural determinant of the protein behind this selectivity. As reported previously, the active and substrate binding site of both proteins is to a large extent very similar $[22,38]$. However, a closer inspection reveals that the region corresponding to the binding pocket for steroids in the human enzyme is partially occluded by Y295 in the parasite enzyme (Figure 7A). Y295 belongs to the C-terminal dimerization domain of the protein and is located in a largely disordered region that allows the lateral chain of this residue to face and make contact with residues from the Rossmann-fold domain. Furthermore, the looser conformation of this region, which can be seen as a lid over the G6P binding site, allows G6P to locate deeper into the active site and consequently to free space 
in a pocket accessible to the solvent, where the steroids bind. In contrast, the equivalent residue of human G6PDH, namely Y249, is located in a well packed $\alpha$-turn and facing the solvent. In this conformation, a narrow cleft is formed between both protein domains, which allows for sandwiching the steroids in the human enzyme. The narrowness of the steroid binding site in the human enzyme, which imposes important steric restrictions to the ligands, may also explain why inhibition of the human enzyme by certain steroids proves to be more difficult than TcG6PDH.
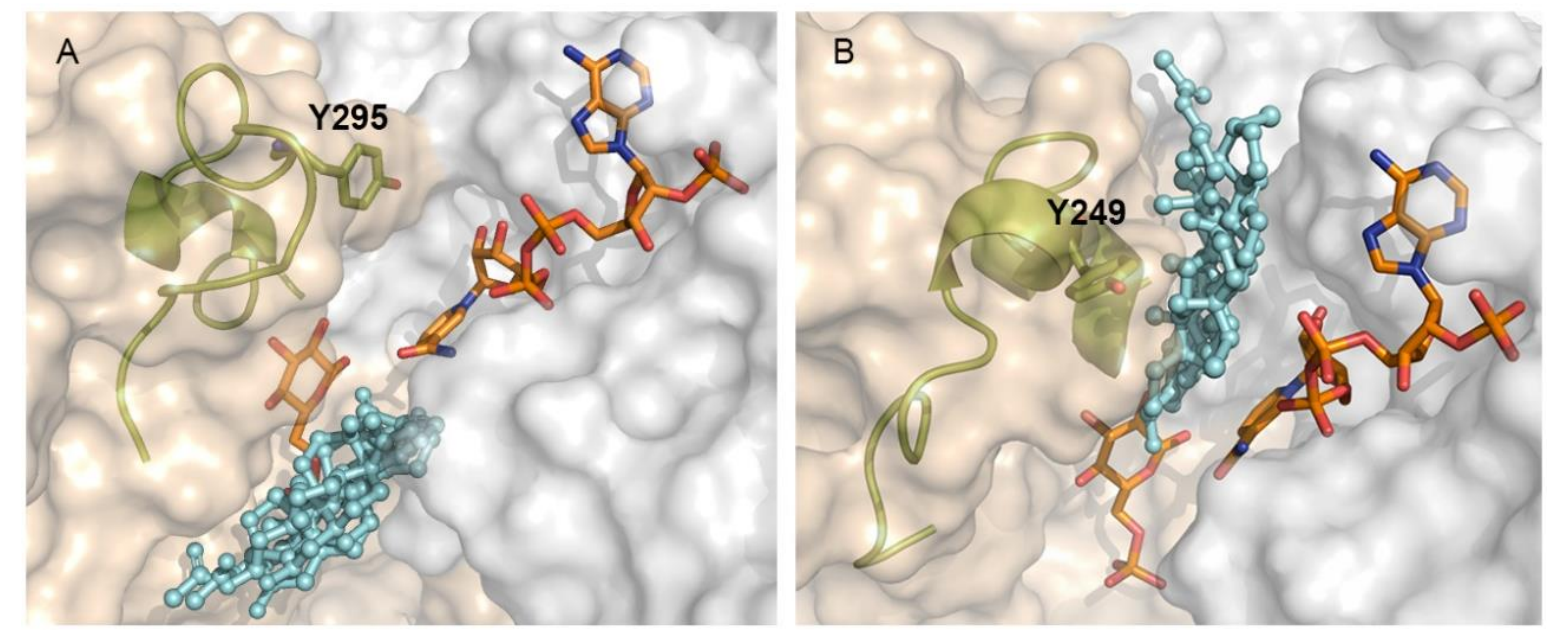

Figure 7. Differential binding site of steroids derivatives to T. cruzi and human G6PDH. (A) Catalytic model of TcG6PDH (left side) and (B) HsG6PDH (right side), $\mathrm{NADP}^{+}$and G6P are shown as orange sticks. Steroid derivatives (cyan balls and sticks). The element containing the tyrosine residue (Y295 and Y249 in Tc- and Hs-G6PDH) is shown as cartoons and olive colored sticks. The N-terminal Rossmann-fold and the C-terminal dimerization domain of TcG6PDH are shown as having their surfaces colored in light-gray and wheat color, respectively.

\subsection{Biological Activity of Steroid Derivatives}

The biological activity of the compounds was tested against epimastigotes of T. cruzi, bloodstream T. brucei brucei and murine macrophages (cell line J774).

None of the compounds caused a significant cytotoxic effect on T. cruzi when tested at 1 and $10 \mu \mathrm{M}$ for $72 \mathrm{~h}$ (not shown). At $50 \mu \mathrm{M}$ (Table 2), the brominated and acetoxy-substituted analogues $(2,3,5$ and 6) proved to be significantly more active (cytotoxicity 30-76\%) than the related derivatives lacking one $(\mathbf{1}, 4)$ or both substitutions (EA, 7; cytotoxicity $4-15 \%)$. The acetoxy analogues of EA and DHEA with the $\mathrm{Br}$ atom in $\beta$ orientation displayed the highest cytotoxic effect (3: 74\% and 6: 76\%). Strikingly, the most potent inhibitor of TcG6PDH, compound 1 ( $\mathrm{IC}_{50} 53 \mathrm{nM}$ ), affected cell viability to a minor extent (15\%) when compared to compound 6 (cytotoxicity of $76 \%$ ), which has a 1000 -fold lower inhibitory activity against TcG6PDH $\left(\mathrm{IC}_{50}>50 \mu \mathrm{M}\right)$. This clearly suggests that certain steroid analogues in vivo inhibit other essential molecular targets beyond G6PDH with a higher affinity.

With the exception of the un-substituted analogues (EA, DHEA and $\left.7=\mathrm{EC}_{50}>24-44 \mu \mathrm{M}\right)$, all derivatives displayed a significantly higher cytotoxic effect against bloodstream T. brucei (EC $\mathrm{E}_{50}$ 2-18 $\mu \mathrm{M}, 24 \mathrm{~h}$ incubation) than towards T. cruzi epimastigotes (estimated $\mathrm{EC}_{50} \geq 50 \mu \mathrm{M}$, $72 \mathrm{~h}$ incubation). For T. brucei, compared to EA $\left(\mathrm{EC}_{50}=36.5 \mu \mathrm{M}\right)$ and DHEA $\left(\mathrm{EC}_{50}=43.8 \mu \mathrm{M}\right)$, the $\mathrm{EC}_{50}$ for compounds 1-3 and 4-6 was from 7- to 19-fold and from 2- to 8-fold higher, respectively. Several of the new analogues displayed a similar or higher potency than the control drug Nifurtimox $\left(\mathrm{EC}_{50}=6.0 \mu \mathrm{M}\right)$, although none of them reached the submicromolar potency of Conessine $\left(\mathrm{EC}_{50}=0.42 \mu \mathrm{M}\right)$ [44]. 
Table 2. Biological activity of (dehydro)epiandrosterone derivatives.

\begin{tabular}{|c|c|c|c|c|}
\hline \multirow[b]{2}{*}{ Compound } & $\%$ Cytotoxicity $(50 \mu \mathrm{M})^{a}$ & $\mathrm{EC}_{50}(\mu \mathrm{M})^{\mathrm{a}}$ & $\mathrm{CC}_{50}(\mu \mathrm{M})^{\mathrm{a}}$ & \multirow[b]{2}{*}{ Selectivity Index ${ }^{b}$} \\
\hline & $\begin{array}{c}\text { T. Cruzi } \\
\text { Epimastigote Form }\end{array}$ & $\begin{array}{c}\text { T. brucei } \\
\text { Bloodstream Form }\end{array}$ & $\begin{array}{l}\text { Murine Macrophage } \\
\text { (Cell Line J774) }\end{array}$ & \\
\hline EA & $3.7 \pm 0.7$ & $36.5 \pm 3.6^{c}$ & $>100$ & $>2.7$ \\
\hline 1 & $14.5 \pm 5.3$ & $1.9 \pm 0.2$ & $8.8 \pm 1.0$ & 4.6 \\
\hline 2 & $64.0 \pm 4.1$ & $5.3 \pm 0.4$ & $42.0 \pm 1.0$ & 7.9 \\
\hline 3 & $73.9 \pm 3.4$ & $4.8 \pm 0.5$ & $1.0 \pm 0.1$ & 0.2 \\
\hline DHEA & n.d. & $43.8 \pm 2.0^{c}$ & $25.0 \pm 13.0^{d}$ & 0.6 \\
\hline 4 & $6.4 \pm 1.6$ & $7.5 \pm 0.3$ & $19.0 \pm 3.0$ & 2.5 \\
\hline 5 & $30.9 \pm 2.5$ & $18.0 \pm 3.0$ & $39.0 \pm 3.0$ & 2.2 \\
\hline 6 & $76.2 \pm 0.8$ & $5.3 \pm 0.5$ & $4.5 \pm 0.4$ & 0.9 \\
\hline 7 & $3.9 \pm 0.7$ & $>24$ & $>24$ & n.d \\
\hline Conessine & n.d. & $0.42 \pm 0.01^{\mathrm{e}}$ & $61.2^{\mathrm{e}}$ & 145.7 \\
\hline Nifurtimox & $46.0 \pm 1.9($ at $24 \mu \mathrm{M})$ & $6.0 \pm 0.4$ & $140.0 \pm 2.0$ & 23.3 \\
\hline
\end{tabular}

${ }^{a}$ Data presented as mean value \pm standard deviation of at least three independent determinations. ${ }^{b}$ The selectivity index (SI) was calculated as the ratio: $\mathrm{CC}_{50}$ for murine macrophages/ $\mathrm{EC}_{50}$ for $T$. brucei. ${ }^{\mathrm{c}}$ value reported by [44]. ${ }^{\mathrm{d}}$ value reported against Hek293T by [27]. e Values against mammalian L6 cell line from rat skeletal myoblasts reported by [44]. n.d. not determined.

With respect to mammalian cells, except for $5\left(\mathrm{CC}_{50}=39.0 \mu \mathrm{M}\right)$ and $7\left(\mathrm{CC}_{50}>24 \mu \mathrm{M}\right)$, the remaining analogues also proved to be more cytotoxic than EA and DHEA. Notably, the most cytotoxic compounds from each class were the 3-acetoxy, $16 \beta$-brominated analogues $3\left(\mathrm{CC}_{50}=0.96 \mu \mathrm{M}\right)$ and $6\left(\mathrm{CC}_{50}=4.5 \mu \mathrm{M}\right)$ with $\mathrm{CC}_{50}$ values near 100- and 6-fold higher than those of EA and DHEA, respectively. In consequence, these compounds, as well as DHEA, proved the less selective against the pathogen. In contrast, compounds 1 (SI $=4.6)$ and $2(\mathrm{SI}=8)$, and $4(\mathrm{SI}=2.5)$ and $\mathbf{5}(\mathrm{SI}=2.2)$ showed similar or better selectivity than EA $(\mathrm{SI}>2.7)$ and DHEA $(\mathrm{SI}=0.6)$, respectively.

Besides the differences pointed above for the biological activity of the compounds, there was no correlation between inhibition of trypanosomal G6PDH and anti-trypanosomal or mammalian cytotoxicity for all EA and DHEA derivatives. Such behavior is particularly intriguing for compounds $\mathbf{2}$ and $\mathbf{5}$, which displayed the highest in vitro selectivity towards the TcG6PDH enzyme. A possible explanation for this is that enzymatic hydrolysis of the acetoxy group (e.g., by esterases) affords the alcohol derivative at position 3, which may present a lower affinity for TcG6PDH. In contrast, similar products of the $\beta$-brominated derivatives 3 and $\mathbf{6}$ may render these compounds more active against human G6PDH or, eventually, may have other molecular targets.

\subsection{Steroid Derivatives Affect the Intracellular Redox State of Bloodstream T. brucei}

Several factors may account for the aforementioned lack of correlation between trypanosomal G6PDH inhibition in vitro and biological potency. Examples of these factors include compound uptake and metabolization/conversion, all of which may reduce the intracellular content of the active form of the original compounds. In some cases, the metabolized compounds may gain affinity for new molecular targets. In the absence of efficient $\mathrm{NADPH}^{+}$-synthesizing backup systems, inhibition of G6PDH should lead to a decrease in the $\mathrm{NADPH}^{+} / \mathrm{NADP}^{+}$ratio. Among other functions, $\mathrm{NADPH}^{+}$is required to maintain the intracellular pool of low molecular weight and protein thiols in reduced form [45]. On the other hand, inhibition of G6PDH has consequences on the downstream output of the PPP pathway, i.e., it causes a shortage of ribose 5-phosphate that impairs cell proliferation (the cytostatic effect). Thus, in order to verify the on-target effect of the steroid derivatives and their metabolic effect in the pathogen, we used a redox-reporter cell line of bloodstream T. brucei [46]. Based on the higher potency of the derivatives against bloodstream T. brucei and the fact that this parasite stage represents a clinically more relevant biological model to investigate compounds mode of action, the studies were performed on this parasite and not on T. cruzi epimastigotes. 
The redox biosensor (hGrx1-roGFP2) [47] consists of a redox sensitive green fluorescent protein (roGFP2) fused to human glutaredoxin 1 (hGrx1) that enables a rapid redox equilibration between roGFP2 and the pool of reduced and oxidized glutathione and trypanothione $[46,48,49]$.

Exponential phase redox-reporter parasites were treated with the steroid analogues added at $2 \times$ their $\mathrm{EC}_{50}$ (EC50), with Conessine at $10 \mathrm{X}$ its $\mathrm{EC}_{50}$ or with vehicle $(1 \% \mathrm{v} / \mathrm{v}$ DMSO). From this study, we excluded all compounds showing poor anti-parasite activity (EA, DHEA and 7). The cells were incubated with compounds only $4 \mathrm{~h}$ prior to analysis, which is less than the doubling time for bloodstream T. brucei $(6-7 \mathrm{~h})$, to obtain a clearer picture of the cause-effect correlation at the onset of the treatment. As control treatments, parasites were shortly exposed to menadione or diamide ( $250 \mu \mathrm{M}$ for $20 \mathrm{~min})$, which consumes $\mathrm{NADPH}^{+}$during redox cycling or is a potent thiol oxidizing agent [50], respectively.

In infective trypanosomes, all steroid derivatives induced an oxidizing intracellular milieu as revealed by the significant 40 to $60 \%$ decrease in the relative amount of reduced biosensor compared to the vehicle control $(p<0.0001$; Figure 8$)$. Notably, the level of oxidation induced by steroids in a $4 \mathrm{~h}$ time-window was similar to that caused in $20 \mathrm{~min}$ by the strong thiol oxidizing agent diamide ( $54 \%$ biosensor oxidation) tested at a 6 -60-fold higher concentration than the compounds. Importantly, to confirm the redox-basis of biosensor oxidation, steroid-treated parasites were exposed to the membrane permeant reducing agent dithiothreitol (DTT $1 \mathrm{mM}$ ) for $20 \mathrm{~min}$. Although to different extent, but in all cases significantly $(p<0.0008)$, a short exposure to DTT was able to restore a more reducing environment in the compound-treated parasites (Figure 8, gray bars).

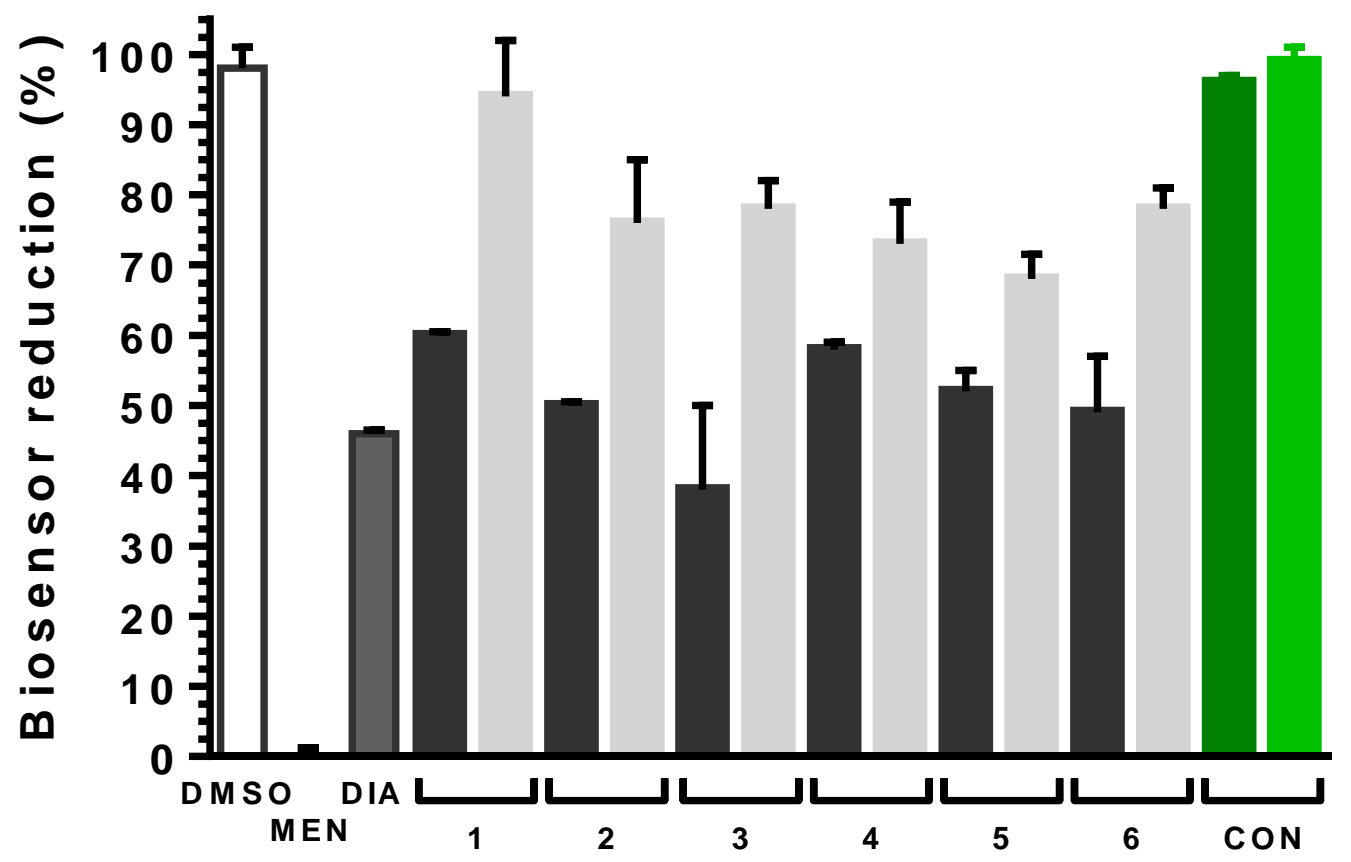

Figure 8. Intracellular redox changes induced by steroid derivatives in bloodstream T. $b$. brucei. Black bars, parasites treated with EA (1, 2 and 3) or DHEA (4, 5 and 6) derivatives at $2 \times$ their corresponding EC 50 values (Table 2) for 4 h; Light gray bars, samples from the corresponding steroid-treated parasites exposed for $20 \mathrm{~min}$ to $1 \mathrm{mM}$ DTT. The white and dark gray bars correspond to parasites treated with vehicle (1\% $v / v$ DMSO) for $4 \mathrm{~h}$ and with $250 \mu \mathrm{M}$ menadiona (MEN) or diamide (DIA) for $20 \mathrm{~min}$. The dark and light green bar correspond to parasites treated with $2 \mu \mathrm{M}$ Conessine $\left(\mathrm{CON}, 5 \times \mathrm{EC}_{50}\right)$ for $4 \mathrm{~h}$ and, thereafter, with $1 \mathrm{mM}$ DTT for $20 \mathrm{~min}$, respectively. The \% biosensor reduction was calculated normalizing the values to the conditions giving full biosensor reduction (parasites treated with 1\% DMSO and DTT 1 mM) and oxidation (parasites treated with $250 \mu \mathrm{M}$ menadione for $20 \mathrm{~min}$ ) and is expressed as mean $\pm \mathrm{SD}$. Each experiment was carried out at least three times. Statistical analysis was performed applying a one-way ANOVA test with $95 \%$ confidence intervals with the Dunnet's multiple comparisons test. 
Although tested at concentrations that should exert a similar cytotoxic effect, the EA derivatives showed the following order of oxidizing potential: $\mathbf{1}<\mathbf{2}<\mathbf{3}(p<0.02)$. A similar trend was observed for the DHEA analogues but the differences were not statistically significant.

Conessine has been previously reported as an inhibitor of trypanothione reductase and trypanothione syntethase [51]. Inhibition of these indispensable molecular targets should entail a significant intracellular redox unbalance [52-54]. However, in line with the observed lack of activity towards the trypanosomal G6PDH (Table 1), Conesine, at $5 \times$ its $\mathrm{EC}_{50}$ (or even $24 \times$ its $\mathrm{EC}_{50}$, not shown) did not induce oxidative stress in bloodstream trypanosomes (Figure 8). Taken together, this strongly suggests that this steroid alkaloid, at least in African trypanosomes, have a different mode of action and/or molecular target(s).

In summary, the results demonstrate that all EA and DHEA derivatives targeting in vitro TcG6PDH exert their toxic effects on trypanosomes, at least in part, through alteration of the thiol-redox homeostasis as consequence of a shortage on $\mathrm{NADPH}^{+}$supply that compromises the maintenance of a physiologically high GSH/GSSG and trypanothione/trypanothione disulfide ratio.

\section{Conclusions}

In agreement with digitonin fractionation studies [24], our study confirmed by immuno-and cytochemical-based techniques that G6PDH is mostly a cytosolic and low abundant protein in the non-infective form of T. cruzi. The last finding is in agreement with the fact that amino acid catabolism is the major energy source for this parasite stage and that epimastigotes proved to be less susceptible to steroids than bloodstream T. brucei. In the extracellular stage of the parasites, which dwell in the host bloodstream, lymphatic or interstitial fluids (trypomastigote stage), the supply of reducing power is likely shifted towards the PPP. In these compartments, glucose content is higher than in the insect gut or salivary glands. This metabolic adaptation keeps pace with the fact that extracellular parasites should be prepared to face host oxidative challenge, while intracellular parasites are hidden in a reducing environment and protected from host-cell defenses. In line with this statement, the thiol-redox metabolism of bloodstream T. brucei appeared to be highly sensitive to G6PDH inhibition (see comments below).

The orientation of the $\mathrm{Br}$ atom occupying position 16 of EA and DHEA proved important in determining the potency of the steroids. The $\alpha$-substituted derivatives presented higher activity than those presenting a $\beta$-orientation, which, based on structural analysis, could be ascribed to a more stable binding and steric effect on the catalytic site of the former. The inclusion of an acetoxy group at position 3 of $16 \alpha$-EA and -DHEA, led to the identification of the most selective TcG6PDH inhibitors ever reported (almost three orders of magnitude). The increase in selectivity was mostly due to loss of affinity of the analogues for the human enzyme rather than to a gaining of affinity for the parasitic G6PDH.

The potential binding mode of steroids to host G6PDH has been disclosed and, despite being compatible with the kinetic mechanism of inhibition, proved to differ significantly from that of TcG6PDH. The structure adopted by a short lid-like element near the catalytic site and located in the dimerization domain of G6PDH seems key in determining the species-specific accessibility of steroids to the enzyme active site. Despite contributing to understanding the selectivity observed for steroids, the binding models might be valuable for the rational design of improved inhibitors against both enzymes.

In vitro inhibition of G6PDH by different EA and DHEA derivatives correlated with in-cell enzyme inhibition (in situ G6PDH activity) for T. cruzi epimastigotes and redox unbalance for bloodstream T. brucei. The remarkable intracellular oxidizing milieu induced by a short exposure to steroids highlights the key role of G6PDH in NADPH homeostasis and the lack of complementary and efficient backup systems for the synthesis of this metabolite in bloodstream parasites. Our results also indicate that steroids may have other important molecular targets in trypanosomes and mammalian cells. This is supported by the fact that some steroids lacking inhibitory activity against the T. cruzi $\left(\mathrm{IC}_{50}>50 \mu \mathrm{M}\right)$ or 
human G6PDH ( $\mathrm{IC}_{50}>100 \mu \mathrm{M}$ ) displayed a moderate to significant cytotoxicity towards epimastigotes or murine macrophages $\left(\mathrm{EC}_{50} 1-42 \mu \mathrm{M}\right)$. Although $\mathrm{G} 6 \mathrm{PDH}$ appears to be dispensable for T. cruzi epimastigotes, the killing potential of the steroids and the essentiality of this enzyme should be investigated in the clinically relevant forms of this parasite. Regarding African trypanosomes, G6PDH has been chemically validated here as a drug target.

\section{Materials and Methods}

\subsection{Protein and Ligand Preparation}

To model the binding pose of EA and its derivatives in the T. cruzi G6PDH, we used the enzyme in complex with glucose-6-phosphate and NADPH (PDB ID: 5AQ1) as a starting point and then we modeled the oxidized form of the cofactor by: (i) oxidizing the NADPH to NADP+ (NAP) in place followed by energy minimization (model 1); (ii) extracting the oxidized form of the cofactor from the human coordinates 2BH9 (model 2) and aligning them onto the $5 \mathrm{AQ} 1$ coordinates.

Both models were prepared with the Protein Preparation Wizard [55] in order to add missing $\mathrm{H}$ atoms, to assign the correct ionization state of both substrate and cofactor at physiological $\mathrm{pH}$ using Epik [56,57] and to assign the proper ionization to the amino acids using PROPKA.

For the human G6PDH, we used the PDB coordinates 6E08, representing the enzyme in complex with structural NADP+. The coordinates of the substrate glucose 6-phosphate and of the catalytic NADP+ from the human PDB coordinates 2BHL and 2BH9, respectively, were copied. The full model was then prepared with the Protein Preparation Wizard as well.

EA and its derivatives were prepared using LigPrep [58].

\subsection{Binding Site Detection and Docking}

We performed a binding site analysis of T. cruzi G6PDH model 1 and model 2, and of the human G6PDH model using SiteMap [59-61] at default settings. The model 1 of TcG6PDH consisted of the coordinates for the enzyme co-crystallized with NADPH [37] computationally oxidized to $\mathrm{NADP}^{+}$(NAP) and minimized; for model 2, the atomic coordinates of $\mathrm{NAP}^{+}$were extrapolated from the structure of the co-crystallized human enzyme (PDB 2BH9) and aligned onto the TcG6PDH structure (PDB 5AQ1), since the G6P and NADP sites are highly conserved in both species. A docking study was performed on all the 3 models using Glide [62-65]. For each model, the Glide grid was centered on the highest scored binding site according to the SiteMap Dscore. The Dscore (druggability score) is used to distinguish a "druggable" biding site from an "un-druggable" or "difficult" binding site using the weighted sum of several properties as follows [60,65]:

$$
\text { Dscore }=0.094 \operatorname{sqrt}(\mathrm{n})+0.60 \mathrm{e}-0.324 \mathrm{p} \text {. }
$$

where $\mathrm{n}$ is the number of site points, $\mathrm{e}$ is the enclosure score and $\mathrm{p}$ is the hydrophilic score. Usually, Dscores with values of 1 and above are considered to be "druggable".

The Glide docking was performed using the Standard Precision scoring function (Glide SP), at default settings saving 3 poses per compound.

For the analysis of the binding mode of steroids to TcG6PDH, we chose model 2 because: (i) the binding mode of the cofactor in human G6PDH (PDB 2BH9) was already co-crystallized in the oxidized form that was of interest to us; (ii) as mentioned above, the catalytic site in T. cruzi and human G6PDH is highly conserved; (iii) the predicted binding pose of EA and its derivatives in model 2 is in better agreement with the experimental evidence.

\subsection{Reagents}

Chemical reagents were of analytical or higher grade and obtained from Sigma-Aldrich or AppliChem. Antibiotics were purchased from Invitrogen and Sigma-Aldrich. All protein purification resins and columns were from General Electric Healthcare Life-Sciences (GE). 
The media and the consumables for cell cultures were purchased from Invitrogen and Greiner, respectively.

The chemical syntheses of the compounds were published in [27] and in [44].

\subsection{Expression and Purification of Recombinant Proteins}

E. coli Tuner (DE3) cells were transformed with the pET28a (+) and pHis constructs encoding for $\mathrm{N}$-terminally hexa histidine-tagged $\mathrm{TcG}_{\mathrm{PDH}}$ and $\mathrm{HsG6PDH}$, respectively, and grown overnight in LB medium with $50 \mu \mathrm{g} / \mathrm{L}$ kanamycin and $100 \mu \mathrm{g} / \mathrm{L}$ ampicillin, respectively. ZYM-5052 auto-induction medium with $100 \mu \mathrm{g} / \mathrm{L}$ kanamycin or ampicillin was inoculated at a ratio of 1:100 with overnight cultures and incubated for $4 \mathrm{~h}$ at $37^{\circ}$ and $220 \mathrm{rpm}$. Thereafter, the cultures were incubated for $20 \mathrm{~h}$ at $25^{\circ} \mathrm{C}$ and $170 \mathrm{rpm}$. Cells were harvested by centrifugation $\left(5000 \times g, 10 \mathrm{~min}, 4^{\circ} \mathrm{C}\right)$, resuspended in buffer $\mathrm{A}$ (50 mM Tris, $\mathrm{pH}$ of $8.0,500 \mathrm{mM} \mathrm{NaCl}$ and $5 \mathrm{mM} \mathrm{MgCl}_{2}$ ) containing a complete ${ }^{\mathrm{TM}}$ Protease Inhibitor Cocktail prepared as indicated by the provider (Sigma-Aldrich-Merck, Germany); afterwards, we added $1 \mathrm{mg} / \mathrm{mL}$ of lysozyme and incubated the cells for $1 \mathrm{~h}$ at $4{ }^{\circ} \mathrm{C}$. Cells were further lysed by three cycles of sonication ( $45 \%$ amplitude, $2 \mathrm{~s}$ pulse on/off, for $1 \mathrm{~min}$ ) using a macrotip in a Branson Digital Sonifier 450 (Marshall Scientific, Hampton, VA, USA) and debris was removed by centrifugation at $27,000 \times \mathrm{g}$ for $45 \mathrm{~min}$ at $4{ }^{\circ} \mathrm{C}$ and filtrated through a $0.45 \mu \mathrm{m}$ filter (Millipore-Merck, Darmstadt, Germany). The cleared lysate was loaded onto a HisTrap column pre-equilibrated with buffer A. The column was washed with 10 and 5 column volume of buffer A and $5 \mathrm{mM}$ imidazol in buffer A, respectively, and finally the His-tagged proteins eluted with $500 \mathrm{mM}$ imidazol in buffer A. The fractions containing the recombinant protein were collected, concentrated via ultrafiltration at $4{ }^{\circ} \mathrm{C}$, $7000 \times g(10-\mathrm{kDa}$ filter cutoff) and gel filtrated on a Superdex 200 10/300 GL column preequilibrated with buffer A. Fractions containing the protein of interest, as assessed by Coomasie blue stained SDS 10\% PAGE gels, were collected and tested for enzyme specific activity. Protein concentration was determined from the absorbance values at $280 \mathrm{~nm}$ and the corresponding theoretical absorbance coefficients.

\subsection{G6PDH Enzymatic Assay}

G6PDH activity was determined at room temperature (RT) by monitoring NADPH $\left(\varepsilon_{340}=6220 \mathrm{M}^{-1} \mathrm{~cm}^{-1}\right)$ formation at $340 \mathrm{~nm}$. All reactions were performed in $50 \mathrm{mM}$ Tris (pH 7.5) with $5 \mathrm{mM} \mathrm{MgCl} 2$ and $250 \mathrm{mM} \mathrm{NaCl}$ in a final volume of $500 \mu \mathrm{L}$. The reactions were started by the addition of $700 \mu \mathrm{M} \mathrm{NADP}^{+}$and $6 \mathrm{mM} \mathrm{G6P}$ for TcG6PDH or by the addition of $250 \mu \mathrm{M} \mathrm{NADP}^{+}$and $1 \mathrm{mM}$ G6P for the human enzyme. For each enzyme, a control reaction in the presence of $1 \%(v / v)$ DMSO was run. Stock and working solutions of compounds were prepared in $100 \%(v / v)$ DMSO. For $\mathrm{IC}_{50}$ determinations, at least seven different concentrations of compounds were tested (range: $0.002-50 \mu \mathrm{M}$ ). The initial velocities were calculated from the first $45 \mathrm{~s}$ of the reaction and normalized to the corresponding enzyme control. All measurements were performed at least in triplicate using a Cary 50 Bio spectrophotometer (Agilent Technologies, Santa Clara, CA, USA) at RT. The initial rates were determined with the Origin Pro 8.0 software (OriginLab Corporation, Northampton, MA, USA), and the $\mathrm{IC}_{50}$ values were calculated by nonlinear regression using the GraphPad Prism 5.0 software (GraphPad Inc., San Diego, CA, USA).

\subsection{Generation of T. cruzi Cell Line with Inducible Expression of G6PDH}

Epimastigotes from T. cruzi strains Adriana [66] were grown axenically at $28{ }^{\circ} \mathrm{C}$ in brain-heart tryptose medium (BHT; [67] supplemented with $2 \mathrm{~g} / \mathrm{L}$ glucose, streptomycin $(100 \mu \mathrm{g} / \mathrm{mL})$, penicillin $(100 \mathrm{IU} / \mathrm{mL})$, hemin $(20 \mu \mathrm{g} / \mathrm{mL})$, and 10\% $(v / v)$ heat-inactivated tetracycline-free fetal bovine serum (FBS; PAA, Houston, TX, USA). For inducible expression of TcG6PDHL in T. cruzi strain Adriana, we first generated a cell line expressing the T7 RNA polymerase and tetracycline repressor genes by transforming the parasites with the plasmid pLew13 [68]. Epimastigotes from T. cruzi in the mid-log phase were washed with and resuspended in BHT medium at a final concentration of $5 \times 10^{8}$ parasites $/ \mathrm{mL}$. 
Aliquots of $0.35 \mathrm{~mL}$ were dispensed into disposable 0.4-mm cuvettes (Bio-Rad Laboratories, Hercules, CA, USA) containing $10 \mu \mathrm{g}$ of plasmid DNA and electroporated using a Bio-Rad gene pulser at $335 \mathrm{~V}$ and $1400 \mathrm{mF}$, with two consecutive pulses. After $5 \mathrm{~min}$ on ice, the parasites were diluted 10-fold with BHT containing $10 \%$ FBS and allowed to recover for $24 \mathrm{~h}$ at $28^{\circ} \mathrm{C}$ before adding $200 \mu \mathrm{g} / \mathrm{mL}$ of Geneticin (G418; Life Technologies, Carlsbad, CA, USA). Cells stably transfected with pLew13 were then electroporated with the pTcINDEX-TcG6PDH $\mathrm{P}_{\mathrm{L}}$ construct and transgenic parasites were obtained after 3 weeks of selection with $200 \mu \mathrm{g} / \mathrm{mL}$ G418 and $200 \mu \mathrm{g} / \mathrm{mL}$ hygromycin B (Calbiochem-Merck, Darmstadt, Germany) [69]. The expression of the ectopic copy of TcG6PDHL was induced by growing the parasites in culture medium containing $5 \mathrm{or} 10 \mu \mathrm{g} / \mathrm{mL}$ oxytetracycline (Laboratorios Microsules, Montevideo, Uruguay).

\subsection{Western Blot}

Anti-TcG6PDHL serum was raised in mice (strain Balbc/J) against the purified recombinant TcG6PDHL using a standard immunization protocol approved by the Animal Use and Ethic Committee (CEUA) of the Institut Pasteur Montevideo (Protocol $n^{\circ}$ 005-14) and animals from the in-house specific pathogen free animal facility (Transgenic and Experimental Animal Unit, Institut Pasteur de Montevideo). A total of 10,000,000 to 200,000,000 epimastigotes in the late exponential phase were harvested by centrifugation at $2000 \times g$ for $10 \mathrm{~min}$ at RT and washed twice with phosphate-buffered saline (PBS, $\mathrm{pH} 7.4$ ), incubated for $15 \mathrm{~min}$ in $10 \mathrm{mM}$ Tris-HCl, $1 \mathrm{mM}$ EDTA, $0.5 \%(v / v)$ Triton $\mathrm{X}-100$ at $4{ }^{\circ} \mathrm{C}$ and then centrifuged at $13,000 \times \mathrm{g}$ for $30 \mathrm{~min}$ at $4{ }^{\circ} \mathrm{C}$; afterwards, a SDS-PAGE loading buffer $(30 \mathrm{mM}$ Tris $\mathrm{HCl} \mathrm{pH} 6.6,1 \%(w / v)$ SDS and $5 \%(v / v)$ glycerol) was added to the supernatant followed by two freezing-thawing steps [70]. Proteins from total cell extracts of tet-induced and non-induced parasites and different amounts of recombinant TcG6PDHL were separated by SDS-10\% PAGE under reducing conditions and transferred to a polyvinylidene fluoride (PVDF) membrane (GE-Healthcare, Chicago, IL, USA). The membrane was blocked with PBS- $0.2 \%(v / v)$ and Tween-20 (PBS-T). We then added 5\% $(w / v)$ non-fat dry milk overnight at $4{ }^{\circ} \mathrm{C}$, washed the membrane with PBS-T and incubated with polyclonal mouse serum anti-TcG6PDHL diluted 1:1000 in PBS-T at RT for $2 \mathrm{~h}$. After three washing steps with PBS-T for 5 min each, the membrane was incubated for $1 \mathrm{~h}$ at RT with the corresponding horseradish peroxidase-conjugated goat anti-mouse IgG (Amersham Biosciences, Buckinghamshire, England) as the secondary antibody at a 1:10,000 ratio in PBS-T. The membrane was extensively washed in PBS-T prior to chemoluminiscent detection of reactive bands with the Amersham ECL ${ }^{\text {TM }}$ Western Blotting Detection Reagents (GE Healthcare) and according to the manufacturer's instructions. Finally, films (Amersham hyperfilm ECL, GE Healthcare) were exposed to the membranes during different times (1,5 and $10 \mathrm{~min})$ and were revealed manually for $1 \mathrm{~min}$ in the developing solution (Sigma-Aldrich-Merck, Darmstadt, Germany).

\subsection{Indirect Immunofluorescence}

Five million T. cruzi epimastigotes (strain Adriana) induced or not to express an ectopic copy of $\mathrm{G} \mathrm{PDH}_{\mathrm{L}}$ and grew to the late exponential phase in the absence or presence of $10 \mu \mathrm{g} / \mathrm{mL}$ oxytetracycline were pelleted at $2000 \times \mathrm{g}$ for $10 \mathrm{~min}$ at RT and washed twice with PBS. For fixation, the cells were resuspended in PBS with $4 \%(w / v)$ paraformaldehyde, incubated for 18 min at RT, washed twice with PBS and resuspended in PBS at $\sim 1 \times 10^{5}$ parasites $/ \mu \mathrm{L}$. Drops containing about $50 \mu \mathrm{L}$ of this cell suspension were added to a polilysine treated glass slide (StarFrost, Knittel Glass, Braunschweig, Germany) and incubated overnight at $4{ }^{\circ} \mathrm{C}$. The cells were then permeabilized with $0.2 \%(v / v)$ Triton X-100 in PBS for 20 min and washed twice with PBS. The slides were incubated at $4{ }^{\circ} \mathrm{C}$ overnight and $1 \mathrm{~h}$ with purified mouse polyclonal anti-TcG6PDH (1:1000), anti-LipDH $(1 / 200)$ and rabbit anti- TcTR (1:500), respectively, prepared in PBS added of $0.5 \%(w / v)$ gelatin. Then, the slides were washed with PBS and incubated for $1 \mathrm{~h}$ with the secondary antibody Alexa Fluor ${ }^{\circledR}$ 488-labeled goat anti-mouse IgG and Alexa Fluor ${ }^{\circledR}$ 594-labeled goat 
anti-rabbit IgG, respectively, both of which were added at a final dilution of 1:1000. Nucleic acids were stained with Hoechst 3342 (Invitrogen, Carlsbad, CA, USA) and cell membranes with CellMask Red (Thermofisher). The parasites were visualized with a Leica TCS SP5 spectral confocal microscope and the merge images were generated with the program Adobe Photoshop.

\subsection{Cytochemical Assay for G6PDH Enzymatic Activity}

The inhibition of G6PDH by epiandrosterone (EA) was addressed using non-infective epimastigotes from T. cruzi strain CL-Brener and DM-28c, and an optimized protocol previously described for cytochemical detection of G6PDH activity in mammalian cells [43]. About $5 \times 10^{6}$ cells from an exponential phase culture were treated with 0,25 and $100 \mu \mathrm{M}$ EA for $24 \mathrm{~h}$, then were pelleted at $1800 \times g$ for $10 \mathrm{~min}$ at RT and washed three times with PBS. The cell suspension was then incubated with $20 \mathrm{mM} \mathrm{NADP}^{+}$in buffer B (Tris $50 \mathrm{mM}$ $\left.\mathrm{pH} 7.5,5 \mathrm{mM} \mathrm{MgCl}_{2}\right)$ for $20 \mathrm{~min}$ at $4{ }^{\circ} \mathrm{C}$. The cells were fixed in $4 \%(w / v)$ paraformaldehyde for 30 min at RT, washed twice with $0.2 \%(v / v)$ Triton X-100 in PBS and twice with PBS. After each washing step the cells were pelleted by centrifugation at $1800 \times g$ during 5 min at RT. The permeabilized cells were resuspended in $100 \mu \mathrm{L}$ of buffer B, added to a $600 \mu \mathrm{L}$ reaction buffer $\left(10 \mathrm{mM}\right.$ G6P, $800 \mu \mathrm{M} \mathrm{NADP}^{+}, 0.3 \mathrm{mM}$ phenylmethanesulfonyl fluoride, $5 \mathrm{mM}$ sodium azide, $5 \mathrm{mM}$ cyano-ditolyl tetrazolium chloride and $6 \%(w / v)$ of polyvinyl alcohol, all prepared in buffer B) and incubated for $30 \mathrm{~min}$ at RT. The reaction was stopped with $1 \mathrm{~mL}$ PBS, followed by three washes in PBS and centrifugation at $1000 \times g$ for 3 min at RT. Finally, cells were resuspended in PBS at a density of $1 \times 10^{5}$ cells $/ \mathrm{mL}$ and $50 \mu \mathrm{L}$ of this suspension was added to a polylysine coated microscope slide (StarFrost, Knittel Glass, Germany), followed by incubation overnight at $4{ }^{\circ} \mathrm{C}$. Nucleic acids were stained with DAPI (Fluoroshield Histology Mounting Media, Sigma-Aldrich-Merck, Germany). Cell images (bright field and fluorescence) were obtained with a confocal microscope Leica TCS SP5 and further analyzed and prepared with the program ICy [71] and Adobe Photoshop CS5.

\section{Cell Viability Assays}

T. cruzi epimastigotes (strain DM28) were grown at $28{ }^{\circ} \mathrm{C}$ in LIT medium supplemented with 10\% $(v / v)$ Fetal Bovine Serum (FBS; GIBCO $\left.{ }^{\circledR}\right), 7.5 \mathrm{mM}$ hemin and antibiotics (penicillin $10 \mathrm{U} / \mathrm{mL}$ - streptomycin $10 \mu \mathrm{g} / \mathrm{mL}$ ). To determine parasite viability, $5 \times 10^{5}$ parasites $/ \mathrm{mL}$ in mid- exponential grow phase were seeded in a 96 well-plate $(200 \mu \mathrm{L}$ of the cell suspension/well) containing $2 \mu \mathrm{L}$ of steroid derivatives at different concentrations $(1,10$ and $50 \mu \mathrm{M})$, or $2 \mathrm{uL}$ of vehicle DMSO or Nifurtimox ( $24 \mathrm{uM})$ and incubated during $72 \mathrm{~h}$ at $28{ }^{\circ} \mathrm{C}$. Thereafter, $200 \mu \mathrm{L}$ from each well were transferred to individual cytometer tubes. Propidium iodide (exclusion dye; PI) was added at a final concentration of $2 \mu \mathrm{g} / \mathrm{mL}$ and all samples were analyzed with a BD FACSAria ${ }^{\mathrm{TM}}$ Fusion Cell Sorter (laser/filter pair: $\lambda \mathrm{ex} / \mathrm{em}=561 \mathrm{~nm} 695 \pm 20 \mathrm{~nm}$ for PI). The data were processed and analyzed with the FlowJo-V 10.7.1 software.

Bloodstream T. b. brucei (strain 427- cell line 514-1313) constitutively expressing an ectopic copy of the luminescent red-shifted biosensor LUC [72] was grown in HMI-9 medium complemented with $10 \%(v / v)$ Fetal Bovine Serum Tetracycline-free (FBS; GIBCO ${ }^{\circledR}$, ThermoFisher Scientific, Waltham, MA, USA) in a humidified incubator with $5 \% \mathrm{CO}_{2}$ and at $37^{\circ} \mathrm{C}$. Parasite viability was performed as described in [72]. Briefly, $1 \times 10^{5}$ parasites $/ \mathrm{mL}$ in a mid-exponential growth phase were seeded in a 96 well-plate $(200 \mu \mathrm{L}$ of the cell suspension/well) containing $2 \mu \mathrm{L}$ of steroid derivatives at different concentrations (range: $0.035-50 \mu \mathrm{M}$ ), and incubated over $24 \mathrm{~h}$. Thereafter, $200 \mu \mathrm{L}$ from each well were transferred to a 96-well black plate and incubated with $20 \mu \mathrm{L}$ of a solution containing: $1.5 \mathrm{mg} / \mathrm{mL}$ luciferin in PBS glucose $1 \%(w / v)$ and Triton X-100. The bioluminiscent signal was measured for $5 \mathrm{~s}$ at $37^{\circ} \mathrm{C}$ in a luminometer (LUMI star OPTIMA microplate) over every $8 \mathrm{~min}$ period for a total of $32 \mathrm{~min}$.

Murine macrophages (cell line J774) were cultivated in DMEM medium supplemented with $10 \%(v / v)$ FBS, $10 \mathrm{U} / \mathrm{mL}$ penicillin and $10 \mu \mathrm{g} / \mathrm{mL}$ streptomycin, under a humidified 
$5 \% \mathrm{CO}_{2} / 95 \%$ air atmosphere at $37^{\circ} \mathrm{C}$. Cell viability was assessed using the WST- 1 reagent. For $\mathrm{CC}_{50}$ determination (24-well culture plate), macrophages $\left(6.25 \times 10^{4}\right.$ cells $/ \mathrm{mL} \times$ well $)$ were incubated with different steroid concentrations (range: $0.6-75 \mu \mathrm{M}$ ) during $24 \mathrm{~h}$ at $37^{\circ} \mathrm{C}$.

For all assays, each condition (controls and compounds) was tested in triplicates and cell viability was calculated as follows: viability $(\%)=100 \% \times$ (number of cells for compound $\mathrm{Y}$ at concentration X/number of cells in the DMSO-treated control). $\mathrm{EC}_{50}$ values were obtained from the corresponding concentration/response plots fitted to a sigmoidal Hill equation or extrapolated from nonlinear fitting equations. The errors were calculated using error propagations and are expressed as S.D. estimated as $\sigma^{(\mathrm{n}-1)}$.

\section{Redox Reporter Assay}

Bloodstream T. b. brucei expressing the redox biosensor hGrxroGFP2 was grown as described elsewhere [46]. Briefly, $2 \times 10^{6}$ cells / $\mathrm{mL}$ were seeded per well in a 96-well plate and incubated with different steroids derivatives each at $2 \times$ their $\mathrm{EC}_{50}, 250 \mu \mathrm{M}$ menadione, $250 \mu \mathrm{M}$ diamide or $1 \% v / v$ DMSO for $4 \mathrm{~h}\left(5 \% \mathrm{CO}_{2}\right.$ and $\left.37^{\circ} \mathrm{C}\right)$. Next, $50 \mu \mathrm{L}$ from each well were transferred to a 96-well plate, containing $100 \mu \mathrm{L}$ of sterile PBS with glucose $1 \%(w / v)$. For each condition tested, a second sample was incubated with $1 \mathrm{mM}$ DTT 20 min prior to analysis by flow cytometry, while propidium iodide (exclusion dye; PI) was added at a final concentration of $2 \mu \mathrm{g} / \mathrm{mL}$ All samples were analyzed with a C6Accuri flow cytometer (BD) as described in [46]. GFP fluorescence (filter $\lambda \mathrm{em}=530 / 40 \mathrm{~nm}$ ) was only analyzed for viable cells (PI negative). The data were processed and analyzed with the C6Accuri software. Samples were analyzed in triplicate and the error is expressed as S.D.

Supplementary Materials: The following are available online, Figure S1: In situ detection of G6PDH activity in T. cruzi strain Adriana overexpressing G6PDH, Figure S2: In situ detection of G6PDH activity in T. cruzi strain Dm28c.

Author Contributions: M.A.C. conceived and designed the experiments; M.L. generated the DNA construct and G6PDH-overexpressing T. cruzi (strain Adriana). C.O. and F.M. conducted the biochemical/biological and in silico experiments/analysis, respectively; C.O., F.M. and M.A.C. analyzed the data; M.A.C., N.H. and A.J. contributed reagents/materials/analysis tools; C.O. and M.A.C. wrote the paper. All authors have read and agreed to the published version of the manuscript.

Funding: FOCEM (MERCOSUR Structural Convergence Fund, COF 03/11).

Institutional Review Board Statement: not applicable.

Informed Consent Statement: not applicable.

Data Availability Statement: not applicable.

Acknowledgments: This manuscript is dedicated to the memory of Maurizio Botta († August 2019). CO acknowledges support from ANII (Agencia Nacional de Investigación e Innovación, Uruguay; doctoral fellowship POS_NAC_2012_1_8803) and CSIC (Comisión Sectorial de Investigaciones Científicas, Universidad de la República Uruguay). Caroline Springer and Dan NiculescuDuvaz, both from the Drug Discovery Unit, Cancer Research UK Manchester Institute, UK, are gratefully acknowledged for the kind gift of the steroid derivatives tested in this work. The technical assistance of Soledad Astrada (Cell Biology Unit, Institut Pasteur de Montevideo) and Paula Cespedes (Cell Biology Unit, Institut Pasteur de Montevideo) is gratefully acknowledged. Cristina Quiroga and Andrea Medeiros (Lab. Redox Biology of Trypanosomes, Institut Pasteur de Montevideo) are acknowledged for help in T. cruzi cell culture.

Conflicts of Interest: The authors declare no conflict of interest.

Sample Availability: Samples of the compounds are not available from the authors. 


\section{References}

1. Health Topics. Available online: https://www.who.int/health-topics (accessed on 31 October 2020).

2. Croft, S.L.; Barrett, M.P.; Urbina, J.A. Chemotherapy of trypanosomiases and leishmaniasis. Trends Parasitol. $2005,21,508-512$. [CrossRef] [PubMed]

3. Barrett, M.P.; Croft, S.L. Management of trypanosomiasis and leishmaniasis. Br. Med. Bull. 2012, 104, 175-196. [CrossRef] [PubMed]

4. Stuart, K.; Brun, R.; Croft, S.; Fairlamb, A.; Gürtler, R.E.; McKerrow, J.; Reed, S.; Tarleton, R. Kinetoplastids: Related protozoan pathogens, different diseases. J. Clin. Investig. 2008, 118, 1301-1310. [CrossRef] [PubMed]

5. Comini, M.A.; Ortiz, C.; Cazzulo, J.J. Drug Targets in Trypanosomal and Leishmanial Pentose Phosphate Pathway. In Trypanosomatids Diseases, Molecular Routes to Drug Discovery; Jäger, T., Koch, O., Flohé, L., Eds.; Wiley-Blackwell: Hoboken, NJ, USA, 2013; ISBN 978-3-527-33255-7.

6. Barrett, M.P. The pentose phosphate pathway and parasitic protozoa. Parasitol. Today 1997, 13, 11-16. [CrossRef]

7. Igoillo-Esteve, M.; Maugeri, D.; Stern, A.L.; Beluardi, P.; Cazzulo, J.J. The pentose phosphate pathway in Trypanosoma cruzi: A potential target for the chemotherapy of Chagas disease. An. Acad. Bras. Cienc. 2007, 79, 649-663. [CrossRef]

8. Loureiro, I.; Faria, J.; Santarem, N.; Smith, T.K.; Tavares, J.; Cordeiro-da-Silva, A. Potential Drug Targets in the Pentose Phosphate Pathway of Trypanosomatids. Curr. Med. Chem. 2018, 25, 5239-5265. [CrossRef]

9. Kovářová, J.; Barrett, M.P. The Pentose Phosphate Pathway in Parasitic Trypanosomatids. Trends Parasitol. 2016, 32, 622-634. [CrossRef]

10. Irigoín, F.; Cibils, L.; Comini, M.A.; Wilkinson, S.R.; Flohé, L.; Radi, R. Insights into the redox biology of Trypanosoma cruzi: Trypanothione metabolism and oxidant detoxification. Free Radic. Biol. Med. 2008, 45, 733-742. [CrossRef]

11. Cordeiro, A.T. NADPH Producing Enzymes as Promising Drug Targets for Chagas Disease. Curr. Med. Chem. 2019, $26,6564-6571$. [CrossRef]

12. Kovářová, J.; Nagar, R.; Faria, J.; Ferguson, M.A.J.; Barrett, M.P.; Horn, D. Gluconeogenesis using glycerol as a substrate in bloodstream-form Trypanosoma brucei. PLoS Pathog. 2018, 14, e1007475. [CrossRef]

13. Allmann, S.; Morand, P.; Ebikeme, C.; Gales, L.; Biran, M.; Hubert, J.; Brennand, A.; Mazet, M.; Franconi, J.-M.; Michels, P.A.M.; et al. Cytosolic NADPH homeostasis in glucose-starved procyclic Trypanosoma brucei relies on malic enzyme and the pentose phosphate pathway fed by gluconeogenic flux. J. Biol. Chem. 2013, 288, 18494-18505. [CrossRef] [PubMed]

14. Cordeiro, A.T.; Thiemann, O.H.; Michels, P.A.M. Inhibition of Trypanosoma brucei glucose-6-phosphate dehydrogenase by human steroids and their effects on the viability of cultured parasites. Bioorg. Med. Chem. 2009, 17, 2483-2489. [CrossRef] [PubMed]

15. Kerkhoven, E.J.; Achcar, F.; Alibu, V.P.; Burchmore, R.; Gilbert, I.H.; Trybiło, M.; Driessen, N.N.; Gilbert, D.; Breitling, R.; Bakker, B.M.; et al. Handling Uncertainty in Dynamic Models: The Pentose Phosphate Pathway in Trypanosoma brucei. PLoS Comput. Biol. 2013, 9, e1003371. [CrossRef] [PubMed]

16. Walter, R.D.; Ebert, F. Evidence for NADH- and NADPH-linked glutamate dehydrogenases in Trypanosoma cruzi epimastigotes. J. Protozool. 1979, 26, 653-656. [CrossRef]

17. Barderi, P.; Campetella, O.; Frasch, A.C.; Santomé, J.A.; Hellman, U.; Pettersson, U.; Cazzulo, J.J. The NADP+-linked glutamate dehydrogenase from Trypanosoma cruzi: Sequence, genomic organization and expression. Biochem. J. 1998, 330, 951-958. [CrossRef]

18. Igoillo Esteve, M.; Cazzulo, J.J. The 6-phosphogluconate dehydrogenase from Trypanosoma cruzi: The absence of two inter-subunit salt bridges as a reason for enzyme instability. Mol. Biochem. Parasitol. 2004, 133, 197-207. [CrossRef]

19. Igoillo-Esteve, M.; Cazzulo, J.J. The glucose-6-phosphate dehydrogenase from Trypanosoma cruzi: Its role in the defense of the parasite against oxidative stress. Mol. Biochem. Parasitol. 2006, 149, 170-181. [CrossRef]

20. Leroux, A.E.; Maugeri, D.A.; Opperdoes, F.R.; Cazzulo, J.J.; Nowicki, C. Comparative studies on the biochemical properties of the malic enzymes from Trypanosoma cruzi and Trypanosoma brucei. FEMS Microbiol. Lett. 2011, 314, 25-33. [CrossRef]

21. Leroux, A.E.; Maugeri, D.A.; Cazzulo, J.J.; Nowicki, C. Functional characterization of NADP-dependent isocitrate dehydrogenase isozymes from Trypanosoma cruzi. Mol. Biochem. Parasitol. 2011, 177, 61-64. [CrossRef]

22. Ortíz, C.; Botti, H.; Buschiazzo, A.; Comini, M.A. Glucose-6-Phosphate Dehydrogenase from the Human Pathogen Trypanosoma cruzi Evolved Unique Structural Features to Support Efficient Product Formation. J. Mol. Biol. 2019, 431, 2143-2162. [CrossRef]

23. Bringaud, F.; Rivière, L.; Coustou, V. Energy metabolism of trypanosomatids: Adaptation to available carbon sources. Mol. Biochem. Parasitol. 2006, 149, 1-9. [CrossRef] [PubMed]

24. Maugeri, D.A.; Cazzulo, J.J. The pentose phosphate pathway in Trypanosoma cruzi. FEMS Microbiol. Lett. 2004, $234,117-123$. [CrossRef] [PubMed]

25. Finzi, J.K.; Chiavegatto, C.W.M.; Corat, K.F.; Lopez, J.A.; Cabrera, O.G.; Mielniczki-Pereira, A.A.; Colli, W.; Alves, M.J.M.; Gadelha, F.R. Trypanosoma cruzi response to the oxidative stress generated by hydrogen peroxide. Mol. Biochem. Parasitol. 2004, 133, 37-43. [CrossRef] [PubMed]

26. Mercaldi, G.F.; Ranzani, A.T.; Cordeiro, A.T. Discovery of new uncompetitive inhibitors of glucose-6-phosphate dehydrogenase. J. Biomol. Screen. 2014, 19, 1362-1371. [CrossRef] [PubMed]

27. Hamilton, N.M.; Dawson, M.; Fairweather, E.E.; Hamilton, N.S.; Hitchin, J.R.; James, D.I.; Jones, S.D.; Jordan, A.M.; Lyons, A.J.; Small, H.F.; et al. Novel steroid inhibitors of glucose 6-phosphate dehydrogenase. J. Med. Chem. 2012, 55, 4431-4445. [CrossRef] [PubMed] 
28. Mele, L.; Paino, F.; Papaccio, F.; Regad, T.; Boocock, D.; Stiuso, P.; Lombardi, A.; Liccardo, D.; Aquino, G.; Barbieri, A.; et al. A new inhibitor of glucose-6-phosphate dehydrogenase blocks pentose phosphate pathway and suppresses malignant proliferation and metastasis in vivo. Cell Death Dis. 2018, 9, 572. [CrossRef]

29. Marks, P.A.; Banks, J. Inhibition of mammalian glucose-6-phosphate dehydrogenase by steroids. Proc. Natl. Acad. Sci. USA 1960, 46, 447-452. [CrossRef]

30. Raineri, R.; Levy, H.R. On the specificity of steroid interaction with mammary glucose 6-phosphate dehydrogenase. Biochemistry 1970, 9, 2233-2243. [CrossRef]

31. Gordon, G.; Mackow, M.C.; Levy, H.R. On the mechanism of interaction of steroids with human glucose 6-phosphate dehydrogenase. Arch. Biochem. Biophys. 1995, 318, 25-29. [CrossRef]

32. Gupta, S.; Cordeiro, A.T.; Michels, P.A.M. Glucose-6-phosphate dehydrogenase is the target for the trypanocidal action of human steroids. Mol. Biochem. Parasitol. 2011, 176, 112-115. [CrossRef]

33. Ortiz, C.; Moraca, F.; Medeiros, A.; Botta, M.; Hamilton, N.; Comini, M.A. Binding Mode and Selectivity of Steroids towards Glucose-6-phosphate Dehydrogenase from the Pathogen Trypanosoma cruzi. Molecules 2016, 21, 368. [CrossRef] [PubMed]

34. Cordeiro, A.T.; Thiemann, O.H. 16-bromoepiandrosterone, an activator of the mammalian immune system, inhibits glucose 6-phosphate dehydrogenase from Trypanosoma cruzi and is toxic to these parasites grown in culture. Bioorg. Med. Chem. 2010, 18, 4762-4768. [CrossRef] [PubMed]

35. Au, S.W.; Naylor, C.E.; Gover, S.; Vandeputte-Rutten, L.; Scopes, D.A.; Mason, P.J.; Luzzatto, L.; Lam, V.M.; Adams, M.J. Solution of the structure of tetrameric human glucose 6-phosphate dehydrogenase by molecular replacement. Acta Crystallogr. D Biol. Crystallogr. 1999, 55, 826-834. [CrossRef] [PubMed]

36. Au, S.W.; Gover, S.; Lam, V.M.; Adams, M.J. Human glucose-6-phosphate dehydrogenase: The crystal structure reveals a structural NADP $(+)$ molecule and provides insights into enzyme deficiency. Structure 2000, 8, 293-303. [CrossRef]

37. Kotaka, M.; Gover, S.; Vandeputte-Rutten, L.; Au, S.W.N.; Lam, V.M.S.; Adams, M.J. Structural studies of glucose-6-phosphate and NADP+ binding to human glucose-6-phosphate dehydrogenase. Acta Crystallogr. D Biol. Crystallogr. 2005, 61, 495-504. [CrossRef]

38. Mercaldi, G.F.; Dawson, A.; Hunter, W.N.; Cordeiro, A.T. The structure of a Trypanosoma cruzi glucose-6-phosphate dehydrogenase reveals differences from the mammalian enzyme. FEBS Lett. 2016, 590, 2776-2786. [CrossRef]

39. Zhao, Z.-B.; Liu, Y.; Yao, Y. Computational determination of binding structures and free energies of glucose 6-phosphate dehydrogenase with novel steroid inhibitors. J. Mol. Graph. Model. 2014, 51, 168-172. [CrossRef]

40. Rangel-Aldao, R.; Comach, G.; Mendoza, A. In vitro translation of Trypanosoma cruzi antigens recognized by human chagasic sera. J. Parasitol. 1987, 73, 855-857. [CrossRef]

41. Roldán, A.; Comini, M.A.; Crispo, M.; Krauth-Siegel, R.L. Lipoamide dehydrogenase is essential for both bloodstream and procyclic Trypanosoma brucei. Mol. Microbiol. 2011, 81, 623-639. [CrossRef]

42. Ramos, T.C.; Freymüller-Haapalainen, E.; Schenkman, S. Three-dimensional reconstruction of Trypanosoma cruzi epimastigotes and organelle distribution along the cell division cycle. Cytometry A 2011, 79, 538-544. [CrossRef]

43. Frederiks, W.M.; van Marle, J.; van Oven, C.; Comin-Anduix, B.; Cascante, M. Improved localization of glucose-6-phosphate dehydrogenase activity in cells with 5-cyano-2,3-ditolyl-tetrazolium chloride as fluorescent redox dye reveals its cell cycledependent regulation. J. Histochem. Cytochem. 2006, 54, 47-52. [CrossRef] [PubMed]

44. Nnadi, C.O.; Nwodo, N.J.; Kaiser, M.; Brun, R.; Schmidt, T.J. Steroid Alkaloids from Holarrhena africana with Strong Activity against Trypanosoma brucei rhodesiense. Molecules 2017, 22, 1129. [CrossRef] [PubMed]

45. Manta, B.; Comini, M.; Medeiros, A.; Hugo, M.; Trujillo, M.; Radi, R. Trypanothione: A unique bis-glutathionyl derivative in trypanosomatids. Biochim. Biophys. Acta 2013, 1830, 3199-3216. [CrossRef] [PubMed]

46. Franco, J.; Sardi, F.; Szilágyi, L.; Kövér, K.E.; Fehér, K.; Comini, M.A. Diglycosyl diselenides alter redox homeostasis and glucose consumption of infective African trypanosomes. Int. J. Parasitol. Drugs Drug Resist. 2017, 7, 303-313. [CrossRef]

47. Gutscher, M.; Pauleau, A.L.; Marty, L.; Brach, T.; Wabnitz, G.H.; Samstag, Y.; Meyer, A.J.; Dick, T.P. Real-time imaging of the intracellular glutathione redox potential. Nat. Methods 2008, 5, 553-559. [CrossRef]

48. Franco, J.; Medeiros, A.; Benítez, D.; Perelmuter, K.; Serra, G.; Comini, M.A.; Scarone, L. In vitro activity and mode of action of distamycin analogues against African trypanosomes. Eur. J. Med. Chem. 2017, 126, 776-788. [CrossRef]

49. Ebersoll, S.; Bogacz, M.; Günter, L.M.; Dick, T.P.; Krauth-Siegel, R.L. A tryparedoxin-coupled biosensor reveals a mitochondrial trypanothione metabolism in trypanosomes. eLife 2020, 9, e53227. [CrossRef]

50. Gilge, J.L.; Fisher, M.; Chai, Y.-C. The effect of oxidant and the non-oxidant alteration of cellular thiol concentration on the formation of protein mixed-disulfides in HEK 293 cells. PLoS ONE 2008, 3, e4015. [CrossRef]

51. Saudagar, P.; Dubey, V.K. Cloning, expression, characterization and inhibition studies on trypanothione synthetase, a drug target enzyme, from Leishmania donovani. Biol. Chem. 2011, 392, 1113-1122. [CrossRef]

52. Comini, M.A.; Guerrero, S.A.; Haile, S.; Menge, U.; Lünsdorf, H.; Flohé, L. Validation of Trypanosoma brucei trypanothione synthetase as drug target. Free Radic. Biol. Med. 2004, 36, 1289-1302. [CrossRef]

53. Mesías, A.C.; Sasoni, N.; Arias, D.G.; Pérez Brandán, C.; Orban, O.; Kunick, C.; Robello, C.; Comini, M.A.; Garg, N.J.; Zago, M.P. Trypanothione synthetase confers growth, survival advantage and resistance to anti-protozoal drugs in Trypanosoma cruzi. Free Radic. Biol. Med. 2019, 130, 23-34. [CrossRef] [PubMed] 
54. Krieger, S.; Schwarz, W.; Ariyanayagam, M.R.; Fairlamb, A.H.; Krauth-Siegel, R.L.; Clayton, C. Trypanosomes lacking trypanothione reductase are avirulent and show increased sensitivity to oxidative stress. Mol. Microbiol. 2000, 35, 542-552. [CrossRef] [PubMed]

55. Madhavi Sastry, G.; Adzhigirey, M.; Day, T.; Annabhimoju, R.; Sherman, W. Protein and ligand preparation: Parameters, protocols, and influence on virtual screening enrichments. J. Comput. Aided Mol. Des. 2013, 27, 221-234. [CrossRef] [PubMed]

56. Greenwood, J.R.; Calkins, D.; Sullivan, A.P.; Shelley, J.C. Towards the comprehensive, rapid, and accurate prediction of the favorable tautomeric states of drug-like molecules in aqueous solution. J. Comput. Aided Mol. Des. 2010, 24, 591-604. [CrossRef]

57. Shelley, J.C.; Cholleti, A.; Frye, L.L.; Greenwood, J.R.; Timlin, M.R.; Uchimaya, M. Epik: A software program for pK a prediction and protonation state generation for drug-like molecules. J. Comput. Aided Mol. Des. 2007, 21, 681-691. [CrossRef]

58. Schrödinger Release 2020-2: LigPrep; Schrödinger, LLC: New York, NY, USA, 2020.

59. Schrödinger Release 2020-2: SiteMap; Schrödinger, LLC: New York, NY, USA, 2020.

60. Halgren, T.A. Identifying and characterizing binding sites and assessing druggability. J. Chem. Inf. Model. 2009, 49, 377-389. [CrossRef]

61. Halgren, T. New method for fast and accurate binding-site identification and analysis. Chem. Biol. Drug Des. 2007, 69, 146-148. [CrossRef]

62. Schrödinger Release 2020-2: Glide; Schrödinger, LLC: New York, NY, USA, 2020.

63. Friesner, R.A.; Murphy, R.B.; Repasky, M.P.; Frye, L.L.; Greenwood, J.R.; Halgren, T.A.; Sanschagrin, P.C.; Mainz, D.T. Extra precision Glide: Docking and scoring incorporating a model of hydrophobic enclosure for protein-ligand complexes. J. Med. Chem. 2006, 49, 6177-6196. [CrossRef]

64. Halgren, T.A.; Murphy, R.B.; Friesner, R.A.; Beard, H.S.; Frye, L.L.; Pollard, W.T.; Banks, J.L. Glide: A new approach for rapid, accurate docking and scoring. 2. Enrichment factors in database screening. J. Med. Chem. 2004, 47, 1750-1759. [CrossRef]

65. Friesner, R.A.; Banks, J.L.; Murphy, R.B.; Halgren, T.A.; Klicic, J.J.; Mainz, D.T.; Repasky, M.P.; Knoll, E.H.; Shaw, D.E.; Shelley, M.; et al. Glide: A New approach for rapid, accurate docking and scoring. 1. Method and assessment of docking accuracy. J. Med. Chem. 2004, 47, 1739-1749. [CrossRef]

66. Urban, I.; Santurio, L.B.; Chidichimo, A.; Yu, H.; Chen, X.; Mucci, J.; Agüero, F.; Buscaglia, C.A. Molecular diversity of the Trypanosoma cruzi TcSMUG family of mucin genes and proteins. Biochem. J. 2011, 438, 303-313. [CrossRef] [PubMed]

67. Cazzulo, J.J.; Franke de Cazzulo, B.M.; Engel, J.C.; Cannata, J.J. End products and enzyme levels of aerobic glucose fermentation in trypanosomatids. Mol. Biochem. Parasitol. 1985, 16, 329-343. [CrossRef]

68. Wirtz, E.; Leal, S.; Ochatt, C.; Cross, G.A. A tightly regulated inducible expression system for conditional gene knock-outs and dominant-negative genetics in Trypanosoma brucei. Mol. Biochem. Parasitol. 1999, 99, 89-101. [CrossRef]

69. Taylor, M.C.; Kelly, J.M. pTcINDEX: A stable tetracycline-regulated expression vector for Trypanosoma cruzi. BMC Biotechnol. 2006, 6, 32. [CrossRef] [PubMed]

70. Piacenza, L.; Peluffo, G.; Alvarez, M.N.; Kelly, J.M.; Wilkinson, S.R.; Radi, R. Peroxiredoxins play a major role in protecting Trypanosoma cruzi against macrophage- and endogenously-derived peroxynitrite. Biochem. J. 2008, 410, 359-368. [CrossRef] [PubMed]

71. de Chaumont, F.; Dallongeville, S.; Chenouard, N.; Hervé, N.; Pop, S.; Provoost, T.; Meas-Yedid, V.; Pankajakshan, P.; Lecomte, T.; Le Montagner, Y.; et al. Icy: An open bioimage informatics platform for extended reproducible research. Nat. Methods 2012, 9 , 690-696. [CrossRef]

72. Benítez, D.; Dibello, E.; Bonilla, M.; Comini, M.A. A simple, robust, and affordable bioluminescent assay for drug discovery against infective African trypanosomes. Drug Dev. Res. 2020. [CrossRef] 